\title{
Hydro-Thermo-Mechanical Analysis during Injection of Cold Fluid into a Geologic Formation
}

\author{
Seunghee $\mathrm{Kim}^{1 \mathrm{a}}$ and Seyyed A. Hosseini ${ }^{\mathrm{b}}$ \\ ${ }^{a}$ Bureau of Economic Geology, Jackson School of Geosciences, The University of Texas at \\ Austin, 10100 Burnet Rd, Austin, TX 78758, USA (seunghee.kim@wne.edu). \\ ${ }^{b}$ Bureau of Economic Geology, Jackson School of Geosciences, The University of Texas at \\ Austin, 10100 Burnet Rd, Austin, TX 78758, USA (seyyed.hosseini@beg.utexas.edu). \\ Tel) +1 512-471-2360
}

Corresponding author: Seyyed A. Hosseini (seyyed.hosseini@beg.utexas.edu)

\footnotetext{
${ }^{1}$ Present address: Department of Civil and Environmental Engineering, Western New England University, 1215 Wilbraham Rd, Springfield, MA 01119, USA
} 


\begin{abstract}
We conducted in-depth investigations of pore-pressure buildup, temperature, and stress changes under isothermal or nonisothermal injection scenarios, using numerical simulations. The numerical simulation method combines fluid flow, poroelasticity, thermal diffusion, and thermal stress, and is based on the single-phase fluid flow condition. We also examined temporal evolutions of stress states and mobilized friction angles across base, injection zone, and caprock layers for two different stress regimes, normal-faulting and reverse-faulting. Results show that injecting cold fluid shifts an area in which the mobilized friction angle becomes maximum, which is where induced-seismic events are likely to be triggered first, for both stress regimes. We also tested a hypothetical stepwise injection of cold fluid; results show that this injection helps to improve the stability of the injection zone to some extent. Finally, we suggest using dimensionless parameters to determine a prevalence of the thermal-stress effect in the injection zone, and discuss the impact of the initial stress regime and implications of using the single-phase fluid flow condition.
\end{abstract}

Keywords: Fluid injection, Hydro-thermo-mechanical coupling, Poroelasticity, Thermal stress, Induced seismicity. 


\section{Introduction}

Extracting petroleum and natural gas during the era of fossil-fuel dominance has been a major operation that artificially disturbs stress states in geological formations that are generally deeper than $\sim 500 \mathrm{~m}$. In the meantime, efforts-such as $\mathrm{CO}_{2}$ geologic sequestration, enhanced geothermal system (EGS), and wastewater injection-to diversify the energy portfolio and to alleviate the greenhouse gas effect are rendering fluid injection as important as fluid extraction. Injecting fluid into a geological formation could be more complex than extracting fluid for these primary reasons: First, injected fluid, whether similar to an original formation fluid (single-phase fluid flow such as wastewater injection and EGS) or a different one (two-phase flow such as $\mathrm{CO}_{2}$ geologic sequestration and EGS with $\mathrm{CO}_{2}$ ), causes pore-pressure buildup and poroelastic effects. Second, injected fluid (nonisothermal fluid flow such as $\mathrm{CO}_{2}$ geologic sequestration, wastewater injection, and EGS) could retain a different temperature. Poroelastic and thermal stress effects can increase or oppose each other, depending on the condition of the injection/extraction and the bottom-hole temperature of fluids. In particular, injecting fluid colder than an original fluid will cause thermal contraction and corresponding decreases in stresses, which yield an effect opposite of what volume expansion and increases in stresses driven by isothermal fluid injection do. This study focuses on this phenomenon as it can occur in various operations deep under the surface.

These hydro-thermo-mechanical effects have drawn a great deal of attention for the last couple of decades, particularly in regard to energy and/or environmental applications. Salient examples include single-phase isothermal fluid flow [1-4], two-phase isothermal fluid flow [5, 6], single-phase nonisothermal fluid flow [7-9], two-phase nonisothermal fluid flow [10-12], and wellbore heat-transfer problems [13].

In this study, we attempt an in-depth investigation of pore-pressure buildup, thermal diffusion, and stress changes for an isothermal and a nonisothermal cold fluid injection, using numerical simulations. We use the single-phase fluid flow condition to simplify a computation model and thus facilitate a focus on mechanical responses [14]. After the simulations, we examine stress states and mobilized friction angles to determine which layer-bottom, injection, or caprock-approaches most closely a failure criterion under different stress regimes. We also explore a stepwise injection of nonisothermal cold fluid as an alternative to nonisothermal fluid injection with a constant rate. Lastly, we provide discussions on the implications for various energy/environmental applications based on observations from this study. 


\section{Numerical Simulations}

Accounting for both poroelastic and thermal effects during fluid flow in a porous medium greatly increases the complexity of the problem. If this type of problem were to be solved analytically, initial and boundary conditions and geometry should be limited to a simple setting. In this regard, we conducted numerical simulations to investigate spatio-temporal evolutions of poroelastic and thermally-induced stresses and corresponding changes in stability when imposing isothermal or nonisothermal cold-fluid injection with a constant injection rate-the stepwise injection of cold fluid.

\subsection{Simulation Method}

Commercial software COMSOL was used in this study for the simulations of the isothermal or nonisothermal injection of pressurized fluid into a porous medium. We adopted the single-phase fluid flow condition to simplify the problem and thus to facilitate focusing on thermo- and poro-mechanical effects. In COMSOL, we coupled physical modules for the fluid flow in porous media, heat transfer in porous media, and poroelasticity. (Names of built-in modules in COMSOL are Poroelasticity, Solid Mechanics, Heat Transfer in Solids, and Multiphysics [15]).

Fluid flow in porous media complies with mass continuity:

$$
\frac{\partial}{\partial t}\left(\rho_{f} \varphi\right)+\nabla \cdot\left(\rho_{f} \vec{u}\right)=Q
$$

where $t$ is time, $\rho_{f}$ is the mass density of pore fluid, $\varphi$ is the porosity of porous media, and $Q$ is a source of fluid mass. Darcy's velocity vector $\vec{u}$ and the storage model are:

$$
\begin{gathered}
\vec{u}=-\frac{k}{\eta}\left(\nabla p_{f}+\rho_{f} g \nabla z\right) \\
\frac{\partial}{\partial t}\left(\rho_{f} \varphi\right)=\rho_{f} S \frac{\partial p_{f}}{\partial t}
\end{gathered}
$$

where $k$ is the intrinsic permeability, $\eta$ is fluid viscosity, $p_{f}$ is pore-fluid pressure, $g$ is gravity, and $z$ is an vertical coordinate. Equation 3 comes from the combination of Equations 1 and 2. The storage coefficient $S$ is a function of porosity, Biot's coefficient $\alpha$, fluid bulk-modulus $K_{f}$, and solid bulk-modulus $K_{\mathrm{s}}[15]$ :

$$
S=\frac{\varphi}{K_{f}}+(\alpha-\varphi) \frac{1-\alpha}{K_{s}}
$$


Equations 1-3 can be translated into the diffusion formulation:

$$
\rho_{f} S \frac{\partial p_{f}}{\partial t}+\nabla \cdot \rho_{f}\left[-\frac{k}{\eta}\left(\nabla p_{f}+\rho_{f} g \nabla z\right)\right]=-\rho_{f} \alpha \frac{\partial \varepsilon_{v o l}}{\partial t}
$$

where $\varepsilon_{v o l}$ denotes volumetric strain.

Heat transport in porous media is based on the convection-diffusion equation with thermodynamic properties that are volumetrically averaged to account for solid matrix and pore fluid [15]:

$$
\left(\rho_{f} C_{P}\right)_{e q} \frac{\partial T}{\partial t}+\rho_{f} C_{p} u \cdot \nabla T=\nabla \cdot\left(k_{e q} \nabla T\right)+Q^{T}
$$

where $C_{p}$ is the fluid heat capacity at constant pressure, $T$ is temperature, and $Q^{T}$ is the heat source (or sink). The equivalent volumetric heat capacity of porous media $\left(\rho_{f} C_{p}\right)_{e q}$ is decided as:

$$
\left(\rho_{f} C_{p}\right)_{e q}=(1-\varphi) \rho_{d} C_{p, d}+\varphi \rho_{f} C_{p}
$$

where $\rho_{d}$ is the dry density of porous media and $C_{p, d}$ is the heat capacity of dry porous media at constant pressure. The equivalent thermal conductivity of porous media $k_{e q}$ is computed in a similar manner with the thermal conductivity of dry porous media $k_{d}$ and fluid $k_{f}$.

$$
k_{e q}=(1-\varphi) k_{d}+\varphi k_{f}
$$

Note that Equation 8 denotes a weighted average for a parallel model. Weighted averages for parallel and series models are known to represent upper and lower bounds on the effective conductivity, respectively [16], which violate the Hashin-Shtrikman bounds [17, 18]. Using these two geometric mean values would entail an error up to $\pm 40 \%$ given the conductivity ratio $k_{f} / k_{d}=$ $0.58 / 3 \approx 0.2$ [18]. For more discussion in regard to the pore structure and the effective thermal conductivity, refer to $[18,19]$.

Poroelastic models consist of two sets of constitutive equations. In the first set, the first equation relates stress tensor $\sigma$, strain tensor $\varepsilon$, and pore fluid pressure:

$$
\sigma=\vec{C}\left(\varepsilon-\varepsilon^{T}\right)-\alpha p_{f} \vec{I}
$$

Elasticity matrix $\vec{C}$ in Equation 9 must be measured under a drained condition, and $\vec{I}$ is an identity matrix. Thermal strain $\varepsilon^{T}$ is expressed in terms of the coefficient of thermal expansion $\alpha^{T}$ and change from an initial temperature $T-T_{\text {ref }}$ :

$$
\varepsilon^{T}=\alpha^{T}\left(T-T_{r e f}\right)
$$


In the second set of constitutive equations, increment in fluid content $\zeta$ is related to volumetric strain:

$$
p_{f}=M\left(\zeta-\alpha \varepsilon_{v o l}\right)
$$

where Biot's modulus $M$ is an inverse of the storage coefficient $S$. Solid deformation complies with force equilibrium:

$$
\nabla \cdot \sigma+\left(\rho_{f} \varphi+\rho_{d}\right) \vec{g}=\overrightarrow{0}
$$

To summarize, change in fluid content and temperature is fully coupled with strain and stress in our formulation (thermo-poroelasticity). Computation iterates among Equations 1-12 at each time step using a finite-element method during the numerical simulation.

\subsection{Simulation Model and Parameters}

We built a simple simulation model to investigate spatio-temporal evolutions of changes in stresses, driven by both fluid injection and thermal change, at various locations as shown in Figure 1. The left end of the model is an axis of symmetry. Depth to the top of the injection zone, the only layer in the model with a high permeability value, is $1000 \mathrm{~m}$. Thickness of the injection zone is set to $100 \mathrm{~m}$. We conducted numerical simulations with this geometry for three different operations: (1) isothermal fluid injection, (2) nonisothermal cold-fluid injection, and (3) nonisothermal stepwise cold-fluid injection. The left end of the injection zone is the inlet: the constant injection rate is imposed on it during the numerical simulation for the isothermal condition. For the nonisothermal injection condition, the same fluid, but colder than the original by $\Delta T_{i n}=-30 \mathrm{~K}$, is imposed with the same constant injection rate. For the last stepwise nonisothermal injection, the injection rate increases and the injecting temperature decreases several times in a stepwise manner; the total injection time lengthens to achieve the same injection volume in the end. During numerical simulation, we only examine changes such as those in pressure, temperature, strain, and stress, so gravity is turned off.

The right end of the injection zone is set as a fluid outlet. On the top, bottom, left, and right ends of the model no flow condition and thermal-insulation are imposed (except fluid inlet and outlet). In terms of mechanical boundary conditions, rollers are imposed on the left and right ends and at the bottom of the model (i.e., only translational displacement is allowed). The top surface is free to move. The radial and vertical boundaries are $2 \mathrm{~km}$ away from the left and top, respectively. Note that the finite radial dimension is intended so that the model mimics a 
horizontally confined condition rather than a horizontally extensive one. Since we are interested in investigating disturbances from an initial state, the simulation model initially retains zero stress, pore pressure, and strain. The simulation model is also thermally homogeneous, with initial temperature $T_{r e f}=313.15 \mathrm{~K}$ (that is, no geothermal gradient is considered). Table 1 summarizes all parameter values applied during the numerical simulations.

\section{Analyses: Mechanical Stability}

Initial effective stress $\sigma^{\prime}$ can be assessed simply as a function of initial total stress $\sigma_{0}$, initial pore pressure $p_{f 0}$, and Biot's coefficient $\alpha: \sigma^{\prime}=\sigma_{0}-\alpha p_{f 0}$. Vertical and horizontal effective stresses, $\sigma_{v}{ }^{\prime}$ and $\sigma_{h}{ }^{\prime}$, are updated in response to the poroelastic and thermal-stress effects:

$$
\begin{aligned}
& \sigma_{v}^{\prime}=\sigma_{v 0}+\Delta \sigma_{v}^{P}+\Delta \sigma_{v}^{T}-\alpha p_{f} \\
& \sigma_{h}^{\prime}=K \sigma_{v 0}+\Delta \sigma_{h}^{P}+\Delta \sigma_{h}^{T}-\alpha p_{f}
\end{aligned}
$$

where $K$ represents the initial total stress ratio $K=\sigma_{h 0} / \sigma_{v 0}, \Delta \sigma^{P}$ denotes contribution from the poroelastic effect, and $\Delta \sigma^{T}$ represents thermally induced stress. We recorded $\left(\Delta \sigma^{P}+\Delta \sigma^{T}\right)$ and $p_{f}$ at every point during the numerical simulation and then inserted these values into the calculation spreadsheet that was coded on the basis of Equations 13 and 14 to analytically examine changes in the effective stresses.

Two different stress regimes were considered in this study: $K=0.7$ (a normal-faulting stress regime) and $K=1.5$ (a reverse-faulting stress regime). Several assumptions were made for the geometrical setting shown in Figure 1, such as: saturated density of the porous media $\rho_{\text {sat }}=2,650 \mathrm{~kg} / \mathrm{m}^{3}$ and water density $\rho_{f}=1,000 \mathrm{~kg} / \mathrm{m}^{3}$. Initial setting becomes: initial total vertical stress $\sigma_{v 0}=\rho_{s a t} g z$ (e.g., $26 \mathrm{MPa}$ in the injection zone), initial total horizontal stress $\sigma_{h 0}=K \sigma_{v 0}$, and initial pore-pressure $p_{f 0}=\rho_{f} g z$ (e.g., $9.8 \mathrm{MPa}$ in the injection zone). Mobilized friction angle $\phi_{m o b}$ is calculated on the basis of the Coulomb failure criterion to assess a potential for the shear reactivation [11]:

$$
\phi_{m o b}=\arctan \left(\frac{\tau}{\sigma_{n}^{\prime}}\right)
$$

where $\tau$ represents the tangential stress and $\sigma_{n}{ }^{\prime}$ denotes the normal effective stress acting on a fracture. The assumption made for Equation 15 is that cohesionless fractures exist in a critical orientation to the reactivation of shear failure. Friction angle is assumed as $\phi_{f}=30^{\circ}$ : shear 
reactivation occurs when the mobilized friction angle surpasses the friction angle of fractures $\phi_{m o b} \geq \phi_{f}$.

\section{Results and Discussion: Thermo-Poroelastic Behavior}

We present numerical simulation results that shed light on geomechanical responses at a site across a base, an injection, and a caprock layer when isothermal or nonisothermal cold fluid is injected. We focus analysis on three lines of interest: the middle line of the injection zone, the interface between the injection zone and the caprock, and the vertical line located $10 \mathrm{~m}$ away from the injection well. When presenting results, compression is regarded as positive for stress changes.

\subsection{Temperature, Pressure, and Stress Changes along Horizontal Lines}

The areal effect of pressure (and stress) disturbance is broader than the areal effect of hydraulic transport, whereas thermal propagation is slower than hydraulic propagation because it has to cool down ambient rock when the injected fluid is cold [11]. That is, thermal propagation is slower than both pressure propagation and hydraulic transport. Numerical simulation in this study also ascertained this phenomenon by showing that thermal propagation is limited within $200 \mathrm{~m}$ from the injection well after 1 year of injection (Figure 2a), while an increase in pressure extends far beyond the thermal reach (e.g., pressure increase is $\Delta p_{f}>2 \mathrm{MPa}$ at $200 \mathrm{~m}$ away from the injection well; Figure 2b).

Noticeable observation is that temperature drop due to the injection of cold fluid is more pronounced in the inside of the injection zone compared to the interface between the injection zone and the caprock (or base), while the pressure-increase pattern is identical (Figure 2b). At the injection zone-caprock interface, the convective flow of the cold fluid into the caprock is hindered because of the low permeability of caprock. In the meantime, heat is exchanged via conduction with the warmer caprock, which partly counters temperature drop at the interface. Patterns of stress changes are more complicated than shown in the pressure and temperature graphs because of the poroelastic and thermal stress effects. The bottom line is that less temperature drop is reflected in less thermal stress effect: decrease in stresses after 1 year of injection is greater along the middle line of the injection zone than along the interface (Figures $2 \mathrm{c}$ and $\mathrm{d}$ ). Note that the injection zone-caprock interface is likely to experience a shear slip prior 
to the inside of the injection zone because of substantial changes in both horizontal and vertical stresses when isothermal fluid is injected (in case of a normal-faulting stress regime [2]). Observation in this study suggests that the most risky area may shift to the inside of the injection zone, instead of the interface, when cold fluid is injected.

Another observation to note is that the effect of thermal contraction outweighs the poroelastic expansion effect within the range of temperature drop when the cold fluid is injected under the condition $\Delta T_{i n}=-30 \mathrm{~K}$. This is reflected in stress changes along both the interface and the middle line (Figure 3; all results are at the end of injection for each operation). Figure 3 shows that stress changes are positive near the well when the isothermal fluid is injected but that the changes become negative (compression to tension) near the well when the nonisothermal cold fluid is injected.

\subsection{Temperature, Pressure, and Stress Changes along the Vertical Line}

This section scrutinizes stress changes and a likelihood of the shear reactivation for the vertical line, which is drawn $10 \mathrm{~m}$ away from the injection well (Figure 1).

\subsubsection{Pressure, Temperature, and Stresses}

Overpressure, driven by fluid injection, is shown to be nearly homogeneous inside the injection zone in the geometry and material property conditions in this study (Figure 4a; injection zone lies at 1,000-1,100 m depth). Likewise, increase in total stress $\Delta \sigma$ is homogeneous inside the injection zone when the isothermal fluid is injected (Figure $4 \mathrm{c}$ and $\mathrm{d}$ ). Note that vertical stress $\sigma_{z}$ also increases because the rigidity of the upper and lower layers resists the expansion of the injection zone [5]. The volumetric expansion of the injection zone causes compression in the lower part of the caprock and the upper part of the basement close to the injection well, so porepressure and total stresses also increase in these areas (Figure 4a, c, and d). However, tension develops in the radial direction farther away from these injection-zone proximate areas in the caprock and the base as the expansion of the injection zone (and the proximate areas) pushes the

adjacent layers outward (Figure 4c). That is, change in the horizontal stress above and below the reservoir is opposite in sign and much less than that inside the reservoir [20]. The caprock and basement act to absorb the volumetric expansion, dissipating the deformation of the injection zone, so increase in the vertical stress nullifies when moving farther away from the interface. Note that we investigate total radial $\sigma_{r}$ and vertical $\sigma_{z}$ stresses in the numerical simulation 
sections because the axisymmetric simulation model was used. These stresses are also used in the following analyses sections to calculate the horizontal effective $\sigma_{h}{ }^{\prime}$ and vertical effective $\sigma_{v}{ }^{\prime}$ stress in conjunction with pore-pressure change.

When nonisothermal cold fluid is injected, thermal contraction is added to the overpressure-driven compression in the lower part of the caprock and the upper part of the base (see temperature graph in Figure $4 \mathrm{~b}$ ), so the pore-pressure change extends farther vertically from the injection zone than the isothermal fluid injection does (Figure 4a). Stress changes are more drastic. Thermally induced stress outweighs the poroelastic stress, resulting in quite homogeneous tension in the radial direction inside the injection zone (that is, negative $\Delta \sigma_{r}$; Figure 4c). Change in the total radial stress is positive in the lower part of the caprock and the upper part of the base-areas adjacent to the injection zone-driven by the same mechanism that brings tension to those areas when isothermal fluid is injected. Change in the total radial stress diminishes to zero past a peak point that is located a few meters away from the interface with the injection zone. Change in the total vertical stress $\Delta \sigma_{z}$ is also homogeneously negative inside the injection zone, but the absolute decrease is less than that in the radial stress (Figure 4d) as a result of stress redistribution that reflects boundary conditions (roller on the horizontal outside and free on the surface). Change in the total vertical stress is negative across the base, injection zone, and caprock layers.

\subsubsection{Mechanical Stability}

We analyzed first the case in which fluid is injected into the injection zone that is under a normal-faulting stress regime $(K=0.7)$. When injected fluid is isothermal, decreases in the horizontal and vertical effective stress are not significant (less than $\sim \Delta 3 \mathrm{MPa}$; Figure $5 \mathrm{a}$ and $\mathrm{b}$ ) because the poroelastic effect $\Delta \sigma^{P}$ partly counters the negative contribution from the porepressure buildup $\alpha p_{f}$. Similarly, the mobilized friction angle does not undergo conspicuous changes in all areas across the base, injection zone, and caprock. Maximum increase of the angle is observed in the lower part of the caprock and the upper part of base, areas that are a few meters away from the interface with the injection zone (Figure 5c), which is in agreement with a previous study [6].

When injected fluid is colder than the original fluid (nonisothermal), changes in the horizontal and vertical effective stresses reflect competition between the overpressure and thermal drop (Figure 5). The mobilized friction angle exhibits drastic changes; the angle inside 
the injection zone greatly increases $\left(>20^{\circ}\right)$ because of the overwhelming effect of thermal drop and is highest near the upper and lower parts of the injection zone that are located near the caprock and base, respectively. In contrast, the mobilized friction angle in the caprock and the base in the vicinity of the injection zone is reduced to a size smaller than the original value. This reduction corroborates the argument that the reservoir stability is compromised but the caprock stability is rather improved when a reservoir under the normal-faulting stress regime is cooled down during the fluid injection [11]. However, reactivation of fractures in the injection zone could extend to either caprock or base.

Next we analyzed the case in which fluid is injected into the injection zone under a reverse-faulting stress regime $(K=1.5)$. When injected fluid is isothermal, the trend of changes in horizontal and vertical effective stresses is same with the case under the normal-faulting stress regime (Figure $6 \mathrm{a}$ and $\mathrm{b}$ ). Unlike the normal-faulting stress regime, however, the mobilized friction angle at the end of the injection is greater inside the injection zone than in the neighboring layers. The locations of maximum mobilized friction angle emerge at the interface between the injection zone and the caprock/base (Figure 6c), which agrees with a previous study [5].

When injected fluid is nonisothermal, the mobilized friction angle inside the injection zone becomes smaller than that in the vicinity of neighboring layers, and peaks in the lower part of the caprock and in the upper part of the base, at the end of the injection (Figure 6c). This action seems to build consensus with the argument that the lower part of the caprock becomes less stable in the reverse-faulting stress regime [11]. However, the mobilized friction angle at the end of the injection (as shown in Figure 6c) should not be used to contend that the injection zone is more stable than the upper and lower layers; the stress state in the early period of the injection approached the failure criterion more closely than it did at the end of the injection (that is, after 1 year) for the reverse-faulting stress regime. (This will be shown later in Figure 10.) For example, the mobilized friction angle in the injection zone is increased to $\sim 25^{\circ}$ after 9 days of injection (Figure 7c), which pertains to the temporal evolutions of the horizontal and vertical effective stresses along the vertical line (Figure 7a and $\mathrm{b}$ ).

To summarize, analysis of the mobilized friction angle during the fluid injection revealed that the reservoir stability is lowest during the early period then improves with time, whereas the 
caprock/base stability worsens gradually with time. Stress paths at several locations on the vertical line are analyzed in detail in the next section for the corroboration.

\subsubsection{Temporal Evolution of Stresses}

Five locations on the vertical line that is $10 \mathrm{~m}$ away from the injection well were selected for the in-depth investigation of temporal changes in stresses, pressure, and temperature. Selected points are located:

(1) $50 \mathrm{~m}$ above the injection zone-caprock interface (to represent the upper part of the caprock; analogous to $50 \mathrm{~m}$ below the injection zone-base interface),

(2) $5 \mathrm{~m}$ above the injection zone-caprock interface (to represent the lower part of the caprock; analogous to $5 \mathrm{~m}$ below the injection zone-base interface),

(3) on the injection zone-caprock interface (analogous to the injection zone-base interface),

(4) $5 \mathrm{~m}$ below the injection zone-caprock interface (that is, inside the injection zone; analogous to $5 \mathrm{~m}$ above the injection zone-base interface), and

(5) in the middle of the injection zone (refer to the zoomed-in illustration in Figure 1).

When injected fluid is isothermal, points located inside the injection zone (including on the interface) undergo rapid increases in pore pressure and stresses, then converge to a plateau (Figure 8). Note this tendency is due to the outer boundary condition; overpressure would increase linearly with the logarithm of time unless the pressure perturbation cone reaches the outer boundary. Compression in the lower part of the caprock also results in a sharp increase in pore pressure at the point located $5 \mathrm{~m}$ above the interface; thereafter, the elevated pore pressure diffuses gradually with time (Figure 8c), due to slower head changes and faster mechanical changes across the caprock [20-22]. At the point located $50 \mathrm{~m}$ above the interface, change in the radial stress is negative (tension in the radial direction) while that in the vertical stress is positive (compression in the vertical direction), yet the absolute magnitude of change is minute (Figure $8 \mathrm{a}$ and $\mathrm{b})$.

When injected fluid is colder (nonisothermal condition), temporal evolutions of these changes are more complex. At points located inside the injection zone (including on the interface), the total radial stress drops sharply during the initial period and then continues to decrease in a much slower gradient (Figure 9a). In contrast, the total vertical stress bounces back 
after the sharp drop (Figure 9b). We consider this opposite trend to be due partly to the radialdominant flow direction and differing boundary conditions. As the injection of cold fluid continues, the area near the injection well is subject to thermal contraction in the vertical direction as a whole body once the area is thermally homogenized. Subsequently, the vertical compression effect is added, and the vertical stress bounces back after the initial shock passes.

This action, however, does not occur in the horizontal direction, where a roller is imposed on the side boundary (that is, the integrating horizontal strain along any horizontal line is zero) while cold fluid propagates radially toward the outlet, counter to the free condition on the surface. As a result, the tension effect keeps increasing in the radial direction, and the radial stress continues to fall. Pressure buildup inside the injection zone is identical for both isothermal and nonisothermal conditions (compare Figures 8c and 9c); given the same injection volume, we can conclude that the thermal effect does not alter the injection-driven overpressure.

At the point located $5 \mathrm{~m}$ above the interface, stresses sharply jump during the initial period then decrease thereafter as the cooling effect occurs. The pattern of change in pore pressure is rather unique due to the incorporation of poro-thermo-elastic equations: an initial surge, then gradual attenuation as the overpressure diffuses, and then gradually increasing rotation as compression emerges in the lower part of the caprock (Figure 9c). Transient increase in temperature that is caused from an expansion of the caprock (Figure 9d) leads to decrease in fluid pressure after the initial surge because the pore volume increases but the volume of water is maintained. Later, the temperature decreases, which contracts the caprock and therefore, fluid pressure increases due to the decrease in pore volume. At the point located $50 \mathrm{~m}$ above the interface, the total radial stress continues to rise as the thermal contraction of the injection zone (and the area in the vicinity of it) pulls the adjacent layers inward, which is the opposite of what was observed for the isothermal injection. The total vertical stress decreases as the compression in the lower part of the caprock pulls the caprock downward, transmitting tension in the vertical direction.

\subsubsection{Stress Path}

In the previous section, we examined how stress states at the five points evolve during the fluid injection, based on Equations 13 and 14, to delve into the temporal evolution of failure risks. The Coulomb criterion for the reactivation of pre-existing fractures can be expressed in terms of effective principal stresses $\sigma_{1}{ }^{\prime}$ and $\sigma_{3}{ }^{\prime}$, assuming zero cohesion for pre-existing fractures [5]: 


$$
\sigma_{1}^{\prime}=q_{\text {slip }} \sigma_{3}^{\prime}
$$

Slope $q_{\text {slip }}$ in Equation 16 is a function of friction angle:

$$
q_{\text {slip }}=\left[\left(\tan ^{2} \phi_{f}+1\right)^{1 / 2}+\tan \phi_{f}\right]^{2}
$$

If we consider $30^{\circ}$ for the friction angle, slope becomes $q_{\text {slip }}=3$.

Figure 10 ascertains that the stress state approaches the failure criterion more closely when cold fluid is injected than when in the isothermal condition (compare Figure 10a and $\mathrm{b}$ with Figure 10c and d). Stress-path graphs reveal that the point located in the middle of the injection zone approaches the failure criterion most closely, followed by points located on the interface and elsewhere inside the injection zone, when cold fluid is injected under the normalfaulting stress regime (Figure 10c). It is noticeable that the point located $5 \mathrm{~m}$ above the interface moves farther from the failure criterion during the initial period before heading back toward the failure criterion, positioning itself more safely than other points inside the injection zone in terms of the induced seismic activity.

The overall trend of stress paths is similar for the reverse-faulting stress regime (Figure 10d), but the latter elucidates more the importance of the initial stress state. The stress state at the point located in the middle of the injection zone rapidly decreases to almost reach the failure criterion in which the horizontal effective stress is the major principal stress, then turns toward the other failure criterion at around $\sim 9$ days (Figure 10d), accounting for temporal stress evolutions during the injection of cold fluid. This observation implies that evaluating the risk of shear failure at a site may be misleading if based on a final stress state; safety of the injection site is most compromised during the initial period of fluid injection if it is under the reverse-faulting stress regime.

As a side note, we also examined the ratio of change in total stresses to change in pore pressure $\Delta \sigma / \Delta P$, which can be used for analytically determining the maximum sustainable pressure limit [2]. Isothermal condition indicates that most points maintain a constant positive value throughout the injection (Figure 11a and b; the point located $50 \mathrm{~m}$ above the interface is excluded in the graphs due to the scale problem). When the cold fluid ( $\left.\Delta T_{i n}=-30 \mathrm{~K}\right)$ is injected, dominance of the thermal effect causes the ratios to fall to negative values, but the ratios hover between -2 and -1 as the injection time extends beyond 300 days (Figure 11c and d). 


\section{Results and Discussion: Stepwise Injection}

The fluid injection rate affects the bottom-hole temperature at the injection well. When a cold fluid is injected from the surface, the fluid gets warmer because of the heat exchange with ambient rock before arriving at the bottom hole. Therefore, the slower the injection rate, the more heat the fluid gains from the ambient geothermal [13]. In this regard, we can hypothesize that if the injection rate of cold fluid jumps up stepwise, then the bottom-hole temperature of the fluid would correspondingly jump down stepwise, instead of causing a sharp thermal pulse from the beginning. We designed a hypothetical injection condition in which the injection rate increases from $0.15 \mathrm{~kg} / \mathrm{s}$ to $0.3,0.45,0.6,0.75,0.9$, and $1 \mathrm{~kg} / \mathrm{s}$ (Figure 12a) to explore if such a stepwise injection can help alleviate risk of the shear failure. Bottom-hole temperature was presumed to step down from $313.15 \mathrm{~K}$ to $308.15,303.15,298.15,293.15,288.15$, and $283.15 \mathrm{~K}$, corresponding to the jump in the injection rate (Figure 12a). The duration of each injection rate was equally distributed, and the total injection time was lengthened to 617 days to achieve the same injection volume as the previous analysis (constant injection of $1 \mathrm{~kg} / \mathrm{s}$ during 1 year).

\subsection{Temperature, Pressure, and Stress Changes along Horizontal Lines}

Thermal drop is still more pronounced inside the injection zone than on the interface (Figure 12b), which is also true of the constant injection rate of cold fluid. But absolute thermal drop at the end of the injection is abated compared to the previous case (Figure 12b; thin graphs in (b)-(d), from Figure 2, represent results when cold fluid is injected with a constant rate). Injection-driven overpressure was confirmed to be identical to the previous case, which implies the potential advantage of stepwise injection in terms of reducing thermal impact at an injection site.

Changes in the total radial stress $\Delta \sigma_{r}$ also fall to negative in the near field because of the dominance of the thermal effect, but the absolute magnitudes of decreases are smaller than in the previous case of constant injection (Figure 12c). In addition, a location of the maximum stress drop in a horizontal line shifts closer to the injection well. This transition is salient more in the vertical stress: maximum drop in the total vertical stress is located within $\sim 50 \mathrm{~m}$ of the injection well, c.f. $\sim 100 \mathrm{~m}$ away when the cold fluid is injected with the constant injection rate (Figure 12d). These locations of maximum stress decrease coincide with where the temperature gradient is the steepest. 
5.2 Temperature, Pressure, and Stress Changes along the Vertical Line

\subsubsection{Pressure, Temperature, and Stresses}

There is no conspicuous change in the pressure buildup and temperature on the vertical line located $10 \mathrm{~m}$ away from the injection well at the end of the injection, compared to the case in which the cold fluid is constantly injected (Figure $4 \mathrm{a}$ and b). On the other hand, decrease in the total radial stress $\Delta \sigma_{r}$ is abated whereas that in the total vertical stress $\Delta \sigma_{z}$ intensifies inside the injection zone when the stepwise injection is applied (Figure $4 c$ and $d$ ).

\subsubsection{Mechanical Stability}

The two different stress regimes, $K=0.7$ or 1.5 , were again considered here for the geometrical setting shown in Figure 1 and the property conditions used in Section 3.2.2. The first regime examined is the normal-faulting stress (represented with $K=0.7$ ). Total stress changes are reflected in the effective stresses (Figure $5 \mathrm{a}$ and $\mathrm{b}$ ). The mobilized friction angle inside the injection zone is $3^{\circ}-4^{\circ}$ less than the previous constant injection case because of the abated and intensified decrease in total radial stress $\Delta \sigma_{r}$ and total vertical stress $\Delta \sigma_{z}$, respectively (Figure 5c). The mobilized friction angle still peaks near the upper and lower parts of the injection zone that are very close to the caprock and base, respectively. Therefore, stepwise injection of cold fluid is shown to reduce a risk of shear failure inside the injection zone, while maintaining locations of most risky areas and preserving improved stability in the caprock and the base under the normalfaulting stress regime.

Next, the reverse-faulting stress regime $(K=1.5)$ is analyzed. Counter-results between the radial and vertical stresses show that the mobilized friction angle inside the injection zone at the end of the injection is rather increased compared to the previous case (Figure 6). Discrepancies between the mobilized friction angle in the lower part of the caprock and the upper part of the base, where the largest growth in the mobilized friction angle is exhibited, are trivial. As in the previous case, it was discovered that the end of the injection does not belong to the riskiest time: the stress state at the moment after $\sim 542$ days of injection is closest to the failure criterion in this example.

The stability inside the injection zone is greatly improved when comparing the most "dangerous" moments between the constant injection and the stepwise injection (when mobilized friction angle is less than $20^{\circ}$; Figure $7 \mathrm{c}$ ). Therefore, the stepwise injection can help reduce a risk of shear reactivations inside the injection zone as well as delay the riskiest moment, from 9 to 
542 days in this example, while not aggravating (compared to the constant injection) the stability in the lower part of the caprock and the upper part of the base under the reverse-faulting stress regime.

\subsubsection{Temporal Evolution of Stresses}

The four points (excluding one located $50 \mathrm{~m}$ above the interface) on the vertical line in Section 3 were again scrutinized in this section. Pressure exhibits stepwise increases at points that are located inside the injection zone and on the interface (Figure 13c). The point located $5 \mathrm{~m}$ above the interface deviates from this pattern: pressure builds up corresponding to a jump in the injection rate and then gradually decreases until the next jump in the injection rate (Figure 13c). Thermal changes are also stepwise at points inside the injection zone and on the interface, but the temperature decline is smooth at the point in the lower part of the caprock as heat exchange occurs via conduction (Figure 13d). Overall, final values of the overpressure and temperature at points on the vertical line inside the injection zone are similar to those of the previous cases (compare Figure 9 with Figure 13).

Changes in total stresses show a recurring series of the patterns observed when the cold fluid is injected with the constant injection rate (Figure 9a and b), in correspondence with steps in the injection rate and the bottom-hole temperature. Total radial stress decreases abruptly when the injection rate steps up and the bottom-hole temperature steps down and continues to decrease slowly, followed by another sharp drop at a next step at points located inside the injection zone and on the interface (Figure 13a). Total vertical stresses also decrease abruptly, corresponding to the injection rate step-up and bounce-back (as observed in Figure 9), followed by another sharp

drop at a next step (Figure 13b). The absolute maximum decrease in the total vertical stress occurs right after the last step in the injection rate and is smaller than that in the previous case ( $6 \mathrm{MPa}$ vs. 10MPa; Figures $13 \mathrm{~b}$ and $9 \mathrm{~b})$.

The total radial and vertical stresses sharply increase when the injection rate steps up (and the bottom-hole temperature steps down) and then gradually decrease until a next step at the point located $5 \mathrm{~m}$ above the interface.

\subsubsection{Stress Path}


The two stress regimes are again considered in this section. When the stepwise injection is imposed on a reservoir under the normal-faulting stress regime, stress states at the points located in the injection zone and on the interface move toward the failure criterion in a way that greatly reduces the amplitude of the fluctuation compared with the previous case (see Figures 14a and 10c). Stability is still worst at the end of the injection, but the final distance between the failure criterion and the stress state becomes farther (Figure 14a).

The advantage of the stepwise injection is more salient for the reserve-faulting stress regime. Recall that in the previous analysis, the point located in the middle of the injection zone almost touched the failure criterion after $\sim 9$ days of injection (Figure 10d). Every point considered in this study maintains a certain distance from the failure criterion when the stepwise injection is imposed, because of the shortened amplitude of the fluctuation during the evolution of stress states (Figure 14b).

\subsection{Surface Deformation}

Surface deformation at a site can provide valuable information on things such as the overpressure and the reservoir dynamics [23, 24]. Surface deformation at various energy/environment-associated sites has been measured via methods including GPS, EDM, and InSAR [25, 26]. In this study, we examined how the different injection conditions can alter displacements at the surface. The radial displacement is greatest in the middle of the surface (because of the boundary condition), whereas the vertical displacement is largest at the central axis for all injection conditions explored here (Figure 15). Because the surface is free to deform vertically while confined horizontally, vertical displacement is greater than horizontal by one order of magnitude, which is expected. Displacements caused by the cold fluid injection are shown to be smaller than those caused by the isothermal fluid injection, given the same injection volume; thermal contraction partly compensates for the poroelastic volumetric expansion. Therefore, thermal effect should also be incorporated when using surface deformation to inversely evaluate reservoir dynamics such as an injected fluid plume.

Surface-displacement graphs obtained from the stepwise fluid injection lie between the two lines from the isothermal and nonisothermal constant fluid injections (Figure 15). This placement adds support to our argument that the stepwise injection of cold fluid abates the thermal shock that otherwise would be transmitted into the injection zone and surrounding layers. 


\section{Discussion}

In this section we discuss dimensionless numbers related to poroelastic and thermoelastic stresses, impact of the initial stress regime, and implications when the two-phase flow condition prevails.

\subsection{Poroelastic vs. Thermoelastic Stress}

Pressure buildup driven by the injection of an isothermal fluid is proportional to the injection rate $Q$ and fluid viscosity $\eta$, and inversely proportional to the fluid density, thickness of the injection zone $T_{I Z}$, and permeability of this injection zone [27, 28]:

$$
\Delta p_{f} \sim \frac{Q \eta}{4 \pi \rho_{f} T_{I Z} k} f(\xi)
$$

where the Boltzmann variable is $\xi=r /(c t)^{1 / 2}$, in which $r$ denotes radial distance from the injection point, $c$ is the hydraulic diffusivity, and $t$ is injection time. Change in the total stress due to the poroelastic effect $\Delta \sigma^{P}$ can be expressed as a function of Biot's coefficient $\alpha$, Poisson's ratio $v$, and the Boltzmann variable, and is proportional to the increase in pore pressure $[1,2]$ :

$$
\Delta \sigma^{P} \sim \frac{Q \eta}{4 \pi \rho_{f} T_{I Z} k} \frac{\alpha(1-2 v)}{(1-v)} f(\xi)
$$

In this regard, we can construct a proportionality parameter $\pi^{\text {poro }}$ that represents a magnitude of the stress change due to the poroelastic effect during fluid injection:

$$
\pi^{\text {poro }}=\frac{Q \eta}{4 \pi \rho_{f} T_{I Z} k} \frac{\alpha(1-2 v)}{(1-v)} \frac{1}{\xi}
$$

On the other hand, thermally induced stress $\Delta \sigma^{T}$ is proportional to the coefficient of thermal expansion $\alpha^{T}$, temperature change $\Delta T\left(=\left|T-T_{\text {ref }}\right|\right)$, and Young's modulus $E$. We can build a second proportionality parameter $\pi^{\text {thermo }}$ that represents the decrease in the total stress in a three-dimensional setting as a result of thermal drop:

$$
\pi^{\text {thermo }}=\frac{\alpha^{T} \Delta T E}{1-2 v}
$$

Then the competition between decrease in total stress from the thermal effect and increase in total stress from the poroelastic effect can be captured in the dimensionless ratio of these parameters $\pi^{\text {thermo }} / \pi^{\text {poro }}$. 
We conducted additional numerical simulations in which the bottom-hole temperature of injected fluid is colder by $\Delta T_{i n}=-10 \mathrm{~K}$ under the same injection rate; the temperature graph in the near field shrinks vertically by a factor of three compared to the previous case where $\Delta T_{i n}=-30 \mathrm{~K}$ (Figure 16e; after 1 year of injection). Weakened thermal effect is linked to changes in total stresses that hover around zero near the injection well (Figure 16a and b), which means that competition between the poroelastic and thermoelastic stresses is comparable and thus trivial changes are induced in total stresses around the injection well. In one graph, we juxtapose the ratios of dimensionless parameters $\pi^{\text {thermo }} / \pi^{\text {poro }}$ and changes in the total radial stress for each bottom-hole temperature condition at three time elapses (Figure 16c and d). Doing so suggests that the thermally induced stress prevails over the poroelastic stress in the area where $\pi^{\text {thermo }} / \pi^{\text {poro }}$ $>30$, but that the dominance of the thermally induced stress wanes in the area where $\pi^{\text {thermo }} / \pi^{\text {poro }}$ $<20$ for the geometry of reservoir simulated in this study. Note that other geometries may result in different ranges of the $\pi^{\text {thermo }} / \pi^{\text {poro }}$ parameter as to where thermally induced stress dominates over the poroelastic one.

\subsection{Stress Regime}

Temporal changes in the stress state and mechanical stability were analyzed for two different stress regimes in this study: normal-faulting and reverse-faulting. Here is the summary of observations for the two regimes.

Normal-faulting stress regime. If injected fluid is isothermal, maximum increase in the mobilized friction angle occurs in the lower part of the caprock and the upper part of the base in the vicinity of the interfaces with the injection zone. If injected fluid is cold (nonisothermal), increase in the mobilized friction angle is maximum inside the injection zone, especially near the caprock- and base-injection zone interfaces. Stability of the caprock slightly improves after the injection of cold fluid commences. However, note that the location of the maximum mobilized friction angle is close to the interfaces. If cold fluid is injected in a stepwise way, as in the example in this study, stability of the injection zone is improved to some extent, maintaining locations of the maximum mobilized friction angle and enhanced stability of the caprock and the base.

Reverse-faulting stress regime. If injected fluid is isothermal, increase in the mobilized friction angle is greatest at the interface between the injection zone and the caprock/base. If injected fluid is cold (nonisothermal), a risk of shear reactivation shifts across layers as injection 
continues. The mobilized friction angle is greatly increased inside the injection zone and is maximum near the middle of the zone in the early period. Stability in the injection zone is then gradually improved while that in the caprock is continually aggravated as injection continues. The mobilized friction angle is largest in the lower part of the caprock and in the upper part of the base after a certain point in the injection, but it is smaller than the absolute maximum of the mobilized friction angle inside the injection zone during the early period. (Note: Operation time is relatively short in this study, so longer operation could yield different results.) If cold fluid is injected in a stepwise way, the moment when the mobilized friction angle registers its absolute maximum is greatly delayed (9 days vs. 542 days in this study), while maintaining a similar level of stability in the caprock and the base.

\subsection{Single vs. Two-Phase Flow}

We used the single-phase fluid flow condition to explore the poroelastic and thermal stress effect on the redistribution of stresses and the risk of shear reactivations across the base, injection zone, and caprock layers. Observations and results obtained from this condition are directly applicable to operations such as wastewater injection and EGS. On the other hand, twophase (or multiphase) fluid flow condition could better represent other operations such as $\mathrm{CO}_{2}$ geologic sequestration. We discuss anticipated differences in outcomes when different fluids are injected into a reservoir.

One factor to consider is the density difference of the fluids. If the injected fluid is lighter than the original fluid (e.g., $\mathrm{CO}_{2}$ injection into a saline aquifer), it migrates upward. Heavier fluid (e.g., DNAPL) migrates downward. The symmetric development of overpressure and thermal distribution along a vertical line away from an injection well will not be observed in these situations. For example, if cold $\mathrm{CO}_{2}$ (liquid or supercritical state) is injected into a saline aquifer, it migrates both horizontally and upward, causing thermal drop (and overpressure) to be more pronounced in the upper part of the reservoir and the lower part of the caprock [29]. In this regard, density difference and buoyancy effect need to be incorporated into analyses for more reliable outcomes of pressure, temperature, and stress changes.

Another factor to consider is the compressibility of fluids and relative permeability. The compressibility of water, which is comparable to that of rock skeleton, was tested in this study. Injecting a fluid that retains much greater (or less) compressibility may yield a different pattern of pressure buildup. For example, if injected fluid is $\mathrm{CO}_{2}$, whose compressibility is three orders 
of magnitude greater than water's [30], bottom-hole pressure near the injection well is likely to surge and then gradually decrease because of the compressibility of $\mathrm{CO}_{2}$ and the change in the relative permeability [31]. The Joule-Thompson effect can also impact thermal changes at a site (e.g., expansion cooling of injected $\mathrm{CO}_{2}$ can cause a decrease in temperature [29]).

In conclusion, the pressure-increase pattern will be more complex than what Equation 18 anticipates when factors such as density, compressibility, and relative permeability are incorporated [27, 32]; thus, the temporal evolution of stress changes would be different than those from the condition where the same fluid is injected. Nonetheless, discussions about the overall geomechanical responses, such as stress path and mechanical stability, would be still applicable.

\section{Conclusions}

We investigated geomechanical responses at an ideally designed site when isothermal or nonisothermal cold fluid is injected into it, using the numerical simulation method that is based on the single-phase fluid flow condition and combines poroelasticity and thermal stress equations. We also attempted a hypothetical stepwise injection method to explore its possible advantages.

The injection of cold fluid causes thermal contraction to be added to the overpressuredriven compression in the lower part of the caprock and the upper part of the base, so the range of pore-pressure changes extends vertically farther away from the reservoir compared to the range of the isothermal fluid injection. Moreover, total horizontal stress in these areas in the vicinity of the injection zone is subject to positive increase (compression) that is opposite of the negative change (tension) when isothermal fluid is injected. The hypothetical stepwise injection method is shown to alleviate thermal drop in the injection zone: Decrease in the total horizontal stress is abated in the injection zone, whereas that in the total vertical stress is deepened. The areal impact of these stress changes is more confined near the injection well.

Under the normal-faulting stress regime, the maximum mobilized friction angle shifts from in the lower part of the caprock to the inside of the injection zone when the condition changes from isothermal to nonisothermal cold fluid injection, which improves the stability in the caprock. Special attention is required, however, because the location of the maximum 
mobilized friction angle is not far from the caprock and/or base. The hypothetical stepwise injection of cold fluid is shown to improve the stability of the injection zone to some extent.

Under the reverse-faulting stress regime, the maximum mobilized friction angle shifts from at the injection zone-caprock/base interface to the middle of the injection zone for the same change in the injection condition; stability in the injection zone is enhanced while that in the caprock/base is aggravated with time. Thus, it may be misleading if a risk of shear failure is evaluated based on a final stress state: safety of the injection site is most compromised during the initial period of fluid injection. The hypothetical stepwise injection not only helps improve the stability of the injection zone, but also delays the riskiest moment.

Additional analysis implies that the thermally induced stress prevails over the poroelastic stress in the area where $\pi^{\text {thermo }} / \pi^{\text {poro }}>30$, but the dominance of the thermally induced stress

wanes in the area where $\pi^{\text {thermo }} / \pi^{\text {poro }}<20$ for the geometry of reservoir simulated in this study. Observations and results in this study are directly applicable to energy/environmental operations where single-phase flow prevails. However, two-phase (or multi-phase) flow conditions should be considered for operations where the density difference, compressibility of fluids, and relative permeability are significant factors. When the surface deformation is to be used to inversely determine reservoir dynamics, temperature effect should be incorporated into the analysis.

\section{Acknowledgments}

This work was funded by the Gulf Coast Carbon Center at the Bureau of Economic Geology (BEG) and the U.S. Department of Energy, NETL, under contract number DEFE0009301.

\section{References}

[1] Altmann JB, Müller TM, Müller BI, Tingay MR, Heidbach O. Poroelastic contribution to the reservoir stress path. International Journal of Rock Mechanics and Mining Sciences. 2010;47:1104-13.

[2] Kim S, Hosseini SA. Pore pressure/stress coupling during fluid injection and its implications for $\mathrm{CO}_{2}$ geological storage. Under review. 2014.

[3] Schoenball M, Müller T, Müller B, Heidbach O. Fluid-induced microseismicity in pre-stressed rock masses. Geophysical Journal International. 2010;180:813-9.

[4] Vilarrasa V, Carrera J, Olivella S. Hydromechanical characterization of $\mathrm{CO}_{2}$ injection sites. International Journal of Greenhouse Gas Control. 2013;19:665-77.

[5] Rutqvist J, Birkholzer J, Cappa F, Tsang CF. Estimating maximum sustainable injection pressure during geological sequestration of $\mathrm{CO}_{2}$ using coupled fluid flow and geomechanical fault-slip analysis. Energy Conversion and Management. 2007;48:1798-807. 
[6] Rutqvist J, Birkholzer J, Tsang CF. Coupled reservoir-geomechanical analysis of the potential for tensile and shear failure associated with $\mathrm{CO}_{2}$ injection in multilayered reservoir-caprock systems. International Journal of Rock Mechanics and Mining Sciences. 2008;45:132-43.

[7] De Simone S, Vilarrasa V, Carrera J, Alcolea A, Meier P. Thermal coupling may control mechanical stability of geothermal reservoirs during cold water injection. Physics and Chemistry of the Earth, Parts A/B/C. 2013;64:117-26.

[8] Goodarzi S, Settari A, Zoback MD, Keith D. Thermal aspects of geomechanics and induced fracturing in $\mathrm{CO}_{2}$ injection with application to $\mathrm{CO}_{2}$ sequestration in Ohio River Valley. SPE International Conference on $\mathrm{CO}_{2}$ Capture Storage and Utilization: Society of Petroleum Engineers; 2010. p. SPE 139706.

[9] Neuzil C. Hydromechanical coupling in geologic processes. Hydrogeology Journal. 2003;11:41-83.

[10] Preisig M, Prévost JH. Coupled multi-phase thermo-poromechanical effects. Case study: $\mathrm{CO}_{2}$ injection at In Salah, Algeria. International Journal of Greenhouse Gas Control. 2011;5:1055-64.

[11] Vilarrasa V, Olivella S, Carrera J, Rutqvist J. Long term impacts of cold $\mathrm{CO}_{2}$ injection on the caprock integrity. International Journal of Greenhouse Gas Control. 2014;24:1-13.

[12] Vilarrasa V, Silva O, Carrera J, Olivella S. Liquid $\mathrm{CO}_{2}$ injection for geological storage in deep saline aquifers. International Journal of Greenhouse Gas Control. 2013;14:84-96.

[13] Luo Z. Modeling injection induced fractures and their impact in $\mathrm{CO}_{2}$ geological storage. Austin: University of Texas at Austin, Ph.D.; 2013.

[14] Rutqvist J. The geomechanics of $\mathrm{CO}_{2}$ storage in deep sedimentary formations. Geotechnical and Geological Engineering. 2012;30:525-51.

[15] COMSOL. 4.4 User's Guide: COMSOL Inc.; 2013.

[16] Bőttcher C. Theory of Electric Polarisation: Elsevier, Houston; 1952.

[17] Hashin Z, Shtrikman S. A variational approach to the theory of the effective magnetic permeability of multiphase materials. Journal of Applied Physics. 1962;33:3125-31.

[18] Zimmerman RW. Thermal conductivity of fluid-saturated rocks. Journal of Petroleum Science and Engineering. 1989;3:219-27.

[19] Tong F, Jing L, Zimmerman RW. An effective thermal conductivity model of geological porous media for coupled thermo-hydro-mechanical systems with multiphase flow. International Journal of Rock Mechanics and Mining Sciences. 2009;46:1358-69.

[20] Segall P, Fitzgerald SD. A note on induced stress changes in hydrocarbon and geothermal reservoirs. Tectonophysics. 1998;289:117-28.

[21] Gellasch CA, Wang HF, Bradbury KR, Bahr JM, Lande LL. Reverse water-level fluctuations associated with fracture connectivity. Groundwater. 2014;52:105-17.

[22] Verruijt A. Elastic storage of aquifers. Flow Through Porous Media. 1969:331-76.

[23] Vasco DW, Karasaki K, Doughty C. Using surface deformation to image reservoir dynamics.

Geophysics. 2000;65:132-47.

[24] Wang R, Kümpel H-J. Poroelasticity: Efficient modeling of strongly coupled, slow deformation processes in a multilayered half-space. Geophysics. 2003;68:705-17.

[25] Feigl KL, Thurber $\mathrm{CH}$. A method for modelling radar interferograms without phase unwrapping: application to the M5 Fawnskin, California earthquake of 1992 December 4. Geophysical Journal International. 2009;176:491-504.

[26] Newman AV, Dixon TH, Gourmelen N. A four-dimensional viscoelastic deformation model for Long Valley Caldera, California, between 1995 and 2000. Journal of Volcanology and Geothermal Research. 2006;150:244-69.

[27] Hosseini SA, Mathias SA, Javadpour F. Analytical Model for $\mathrm{CO}_{2}$ Injection into Brine AquifersContaining Residual $\mathrm{CH}_{4}$. Transport in Porous Media. 2012;94:795-815.

[28] Wang HF. Theory of Linear Poroelasticity: With Applications to Geomechanics and Hydrogeologoy. New Jersey: Princeton University Press; 2000.

[29] Doughty C, Freifeld B. Modeling $\mathrm{CO}_{2}$ injection at Cranfield, Mississippi: Investigation of methane and temperature effects. Greenhouse Gases: Science and Technology. 2013;3:475-90. 
[30] IPCC. IPCC special report on carbon dioxide capture and storage. In: Metz B, O. Davidson, H. C. de Coninck, M. Loos, and L. A. Meyer, editor. Prepared by working group III of the intergovernmental panal on climate change. Cambridge, United Kingdom and New York, USA: Cambridge University Press; 2005. p. 442.

[31] Okwen RT, Stewart MT, Cunningham JA. Temporal variations in near-wellbore pressures during $\mathrm{CO}_{2}$ injection in saline aquifers. International Journal of Greenhouse Gas Control. 2011;5:1140-8.

[32] Mathias SA, Gluyas JG, González Martínez de Miguel GJ, Hosseini SA. Role of partial miscibility on pressure buildup due to constant rate injection of $\mathrm{CO}_{2}$ into closed and open brine aquifers. Water Resources Research. 2011;47:W12525. 


\section{A List of Figures}

Figure 1. Numerical simulation model used in this study: Geometry, lines of interest (center line of injection zone, interface between injection zone and upper caprock, and vertical line $10 \mathrm{~m}$ away from injection well), and boundary conditions.

Figure 2. Numerical simulation results for the injection of cold fluid. (a) Thermal propagation in the entire simulation model. (b) Temperature and pressure graphs (solid linetemperature along the middle line of the injection zone, dotted line-temperature along the injection zone-caprock interface, and dashed line-pressure along both the middle and interface lines). (c) Change in the total radial stress $\Delta \sigma_{r}$. (d) Change in the total vertical stress $\Delta \sigma_{z}$ in the near field. Note: Results are after 1 year of injection.

Figure 3. Comparison of changes in total stresses among isothermal fluid injection (dashed line), nonisothermal cold fluid injection (solid line), and stepwise injection of nonisothermal cold fluid (dotted line). Changes in (a) total radial stress $\Delta \sigma_{r}$, and (b) total vertical stress $\Delta \sigma_{z}$ at the injection zone-caprock interface. Changes in (c) total radial stress $\Delta \sigma_{r}$, and (d) total vertical stress $\Delta \sigma_{z}$ in the middle of the injection zone.

Figure 4. Changes in pressure, temperature, and stresses along the vertical line located $10 \mathrm{~m}$ away from the injection well. (a) Pressure build-up, (b) temperature, (c) change in total radial stress, and (d) change in total vertical stress at the end of the injection.

Figure 5. Analysis for the normal-faulting stress regime $(\mathrm{K}=0.7)$. Final values at the end of the injection: (a) horizontal effective stress, (b) vertical effective stress, and (c) mobilized friction angle along the vertical line located $10 \mathrm{~m}$ away from the injection well.

Figure 6. Analysis for the reverse-faulting stress regime $(K=1.5)$. Final values at the end of the injection: (a) horizontal effective stress, (b) vertical effective stress, and (c) mobilized friction angle along the vertical line located $10 \mathrm{~m}$ away from the injection well.

Figure 7. Analysis for the reverse-faulting stress regime $(\mathrm{K}=1.5)$ after 9 days (nonisothermal cold fluid injection) and 542 days (stepwise injection of cold fluid) of operation. Values of: (a) horizontal effective stress, (b) vertical effective stress, and (c) mobilized friction angle along the vertical line located $10 \mathrm{~m}$ away from the injection well. 
Figure 8. Temporal evolution of changes in stresses and pressure for the isothermal fluid injection. Change in (a) total radial stress, (b) total vertical stress, and (c) pore pressure. Note: All points are radially $10 \mathrm{~m}$ away from the injection well.

Figure 9. Temporal evolution of changes in stresses, pressure, and temperature for the nonisothermal cold fluid injection. Change in (a) total radial stress, (b) total vertical stress, (c) pore-pressure, and (d) temperature. All points are radially $10 \mathrm{~m}$ away from the injection well.

Figure 10. Stress paths during fluid injection. Isothermal fluid injection: (a) normal-faulting stress regime $(K=0.7)$, and $(b)$ reserve-faulting stress regime $(K=1.5)$. Nonisothermal cold fluid injection: (c) $\mathrm{K}=0.7$, and (d) $\mathrm{K}=1.5$. All points are radially $10 \mathrm{~m}$ away from the injection well.

Figure 11. Ratio of stress change to pore-pressure change during fluid injection. Isothermal fluid injection: (a) radial stress, and (b) vertical stress. Nonisothermal cold fluid injection: (c) radial stress, and (d) vertical stress. All points are radially $10 \mathrm{~m}$ away from the injection well.

Figure 12. Applying a hypothetical stepwise injection of cold fluid: (a) stepwise increase in injection rate and decrease in bottom-hole temperature during the suggested operation, (b) temperature (solid and dotted lines) and pressure (dashed line) graphs, (c) change in the total radial stress, and (d) change in the total vertical stress in the near field. Results are after 617 days of injection.

Figure 13. Temporal evolution of changes in stresses, pressure, and temperature during the stepwise injection of nonisothermal cold fluid. Change in (a) total radial stress, (b) total vertical stress, (c) pore pressure, and (d) temperature. All points are radially 10 m away from the injection well.

Figure 14. Stress paths during the stepwise injection of cold fluid. (a) Normal-faulting stress regime $(K=0.7)$, and (b) reserve-faulting stress regime $(K=1.5)$. All points are radially $10 \mathrm{~m}$ away from the injection well.

Figure 15. Surface deformation at the end of fluid injection. (a) Radial, and (b) vertical deformation with radial distance from injection well.

Figure 16. Comparison between isothermal fluid injection and cold fluid injection at the end of the injection, where $\Delta T_{i n}=-30 \mathrm{~K}$ or $-10 \mathrm{~K}$. (a) Change in the total radial stress, and (b) 
change in the total vertical stress along the middle line of the injection zone. Ratio of dimensionless parameters $\pi^{\text {thermo }} / \pi^{\text {poro }}$ and corresponding change in the total radial stress (thin graphs) when (c) $\Delta T_{i n}=-30 \mathrm{~K}$ and (d) $\Delta T_{i n}=-10 \mathrm{~K}$. (e) Temperature distribution along the middle line (solid) and the interface line (dotted) when $\Delta T_{\text {in }}=$ $-10 \mathrm{~K}$ (thin lines are when $\Delta T_{\text {in }}=-30 \mathrm{~K}$ ). 
1 Table 1 Input parameters for numerical simulations

\begin{tabular}{lcccc} 
& Symbol & \multicolumn{3}{c}{ Value } \\
\cline { 3 - 4 } Property & & Caprock & Injection zone & Base \\
\hline Young's modulus & $\mathrm{E}$ & $30 \mathrm{GPa}$ & $30 \mathrm{GPa}$ & $30 \mathrm{GPa}$ \\
Poisson's ratio & $v$ & 0.25 & 0.25 & 0.25 \\
Dry bulk density & $\rho_{\mathrm{d}}$ & $2000 \mathrm{~kg} / \mathrm{m}^{3}$ & $2000 \mathrm{~kg} / \mathrm{m}^{3}$ & $2000 \mathrm{~kg} / \mathrm{m}^{3}$ \\
Porosity & $\varphi$ & 0.2 & 0.2 & 0.2 \\
Biot's coefficient & $\alpha$ & 1 & 1 & 1 \\
Bulk modulus of fluid & $\mathrm{K}_{\mathrm{f}}$ & $2.2 \mathrm{GPa}$ & $2.2 \mathrm{GPa}$ & $2.2 \mathrm{GPa}$ \\
Density of fluid & $\rho_{\mathrm{f}}$ & $1000 \mathrm{~kg} / \mathrm{m}^{3}$ & $1000 \mathrm{~kg} / \mathrm{m}^{3}$ & $1000 \mathrm{~kg} / \mathrm{m}^{3}$ \\
Viscosity of fluid & $\eta$ & $0.001 \mathrm{~Pa} \cdot \mathrm{s}$ & $0.001 \mathrm{~Pa} \cdot \mathrm{s}$ & $0.001 \mathrm{~Pa} \cdot \mathrm{s}$ \\
Permeability & $\mathrm{k}$ & $1 \mathrm{nD}$ & $100 \mathrm{mD}$ & $1 \mathrm{nD}$ \\
Specific heat of fluid & $\mathrm{C}_{\mathrm{p}}$ & $4.181 \mathrm{~kJ} / \mathrm{kg} / \mathrm{K}$ & $4.181 \mathrm{~kJ} / \mathrm{kg} / \mathrm{K}$ & $4.181 \mathrm{~kJ} / \mathrm{kg} / \mathrm{K}$ \\
Specific heat of solid & $\mathrm{C}_{\mathrm{p}, \mathrm{d}}$ & $0.8 \mathrm{~kJ} / \mathrm{kg} / \mathrm{K}$ & $0.8 \mathrm{~kJ} / \mathrm{kg} / \mathrm{K}$ & $0.8 \mathrm{~kJ} / \mathrm{kg} / \mathrm{K}$ \\
Thermal conductivity of fluid & $\mathrm{k}_{\mathrm{f}}$ & $0.58 \mathrm{~W} / \mathrm{m} / \mathrm{K}$ & $0.58 \mathrm{~W} / \mathrm{m} / \mathrm{K}$ & $0.58 \mathrm{~W} / \mathrm{m} / \mathrm{K}$ \\
Thermal conductivity of solid & $\mathrm{k}_{\mathrm{d}}$ & $3 \mathrm{~W} / \mathrm{m} / \mathrm{K}$ & $3 \mathrm{~W} / \mathrm{m} / \mathrm{K}$ & $3 \mathrm{~W} / \mathrm{m} / \mathrm{K}$ \\
Coefficient of thermal expansion & $\alpha^{\mathrm{T}}$ & $1 \times 10^{-5} / \mathrm{K}$ & $1 \times 10^{-5} / \mathrm{K}$ & $1 \times 10^{-5} / \mathrm{K}$ \\
Injection rate & $\mathrm{Q}_{\text {Q }}$ & \multicolumn{1}{c}{$1 \mathrm{~kg} / \mathrm{s}$ or $0.15 \rightarrow 1 \mathrm{~kg} / \mathrm{s}(\mathrm{stepwise})$} \\
Injection temperature & $\mathrm{T}_{\mathrm{in}}$ & $313.15 \mathrm{or} 283.15$, or $313.15 \rightarrow 283.15 \mathrm{~K}(\mathrm{stepwise})$ \\
Radius of injection well & $\mathrm{r}_{\mathrm{w}}$ & & $0.1 \mathrm{~m}$ & \\
Thickness of injection zone & $\mathrm{T}_{\mathrm{IZ}}$ & & $100 \mathrm{~m}$ & \\
Depth to top of injection zone & $\mathrm{D}_{\mathrm{IZ}}$ & & $1000 \mathrm{~m}$ & \\
Simulation time & $\mathrm{t}_{\mathrm{simul}}$ & $365 \mathrm{days}(\mathrm{constant}$ injection$) \mathrm{or} 617 \mathrm{days}(\mathrm{stepwise})$
\end{tabular}




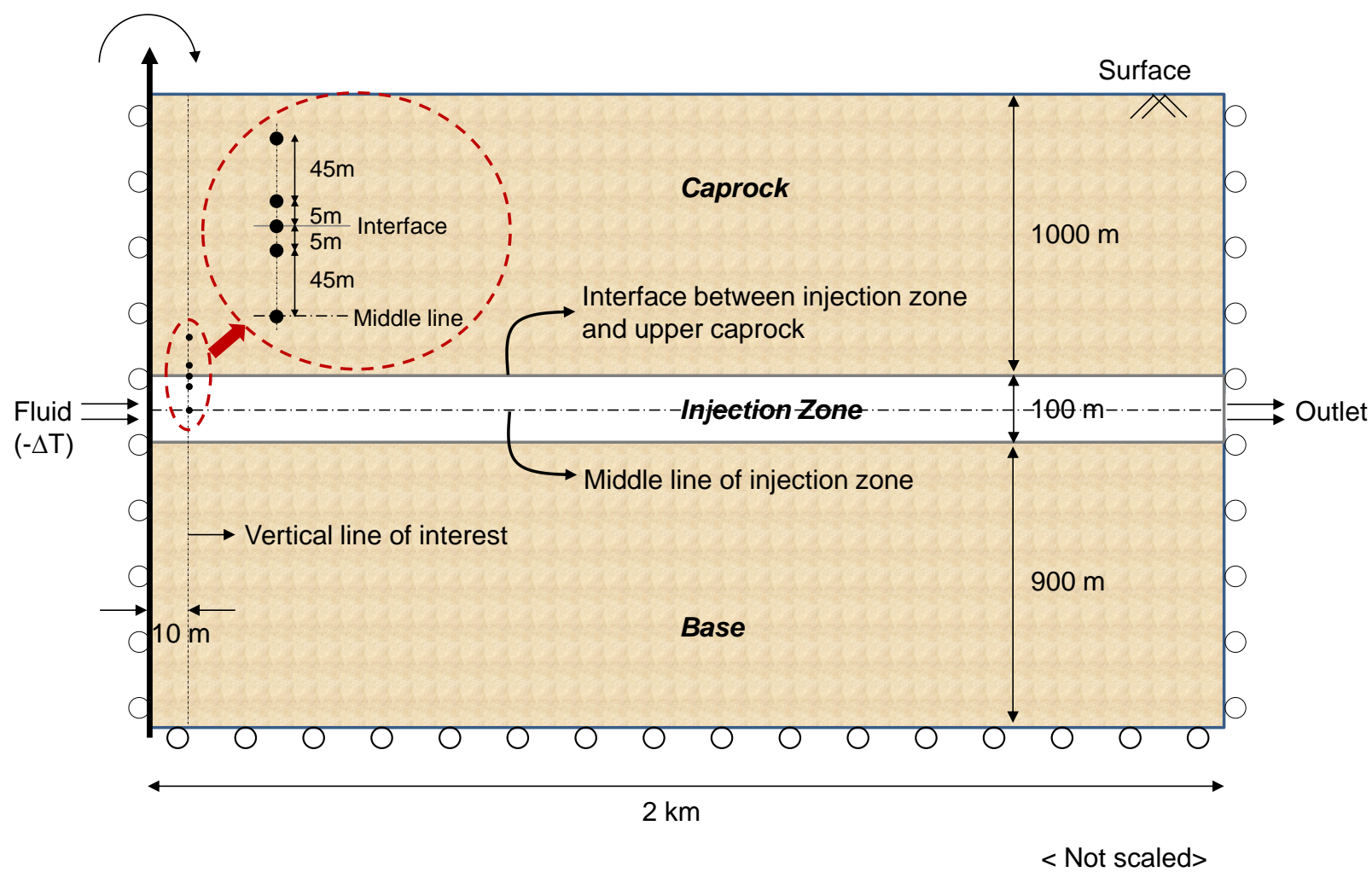

Fig. 1 Numerical simulation model used in this study: Geometry, lines of interest (center line of injection zone, interface between injection zone and upper caprock, and vertical line $10 \mathrm{~m}$ away from injection well), and boundary conditions. 


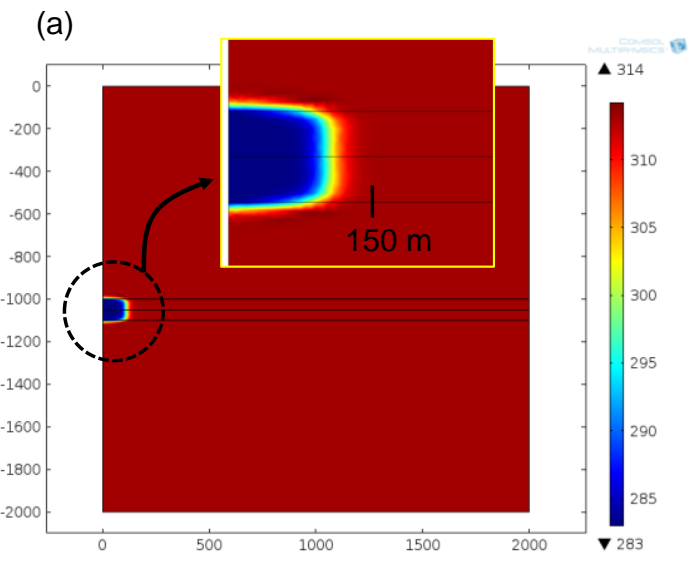

(c)

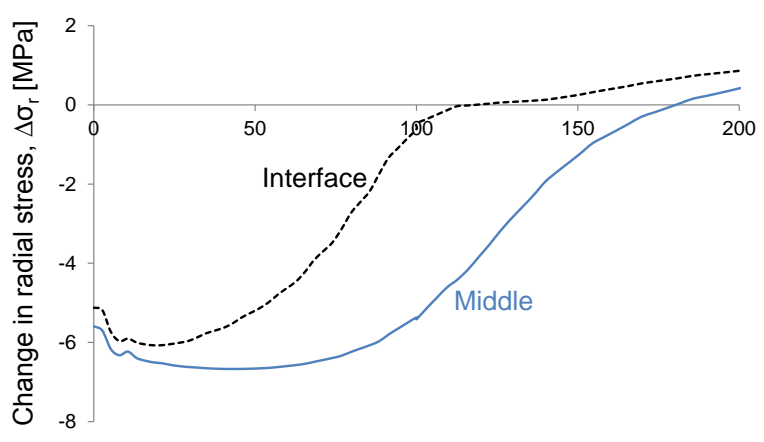

(b)

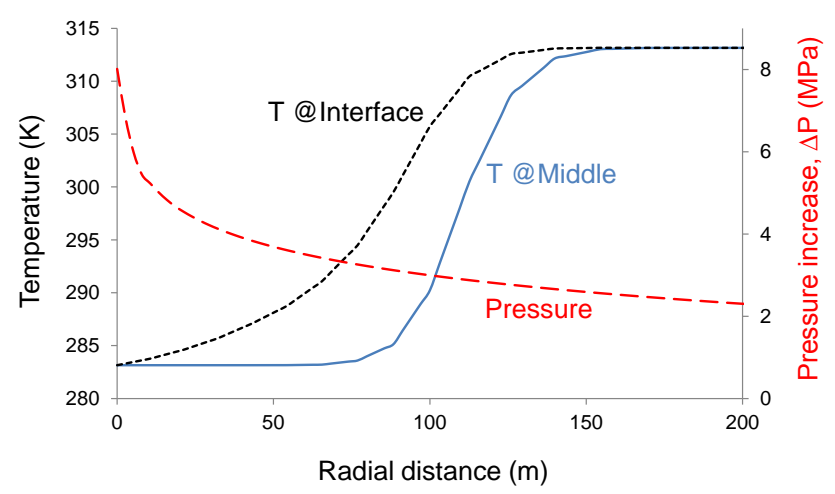

(d)

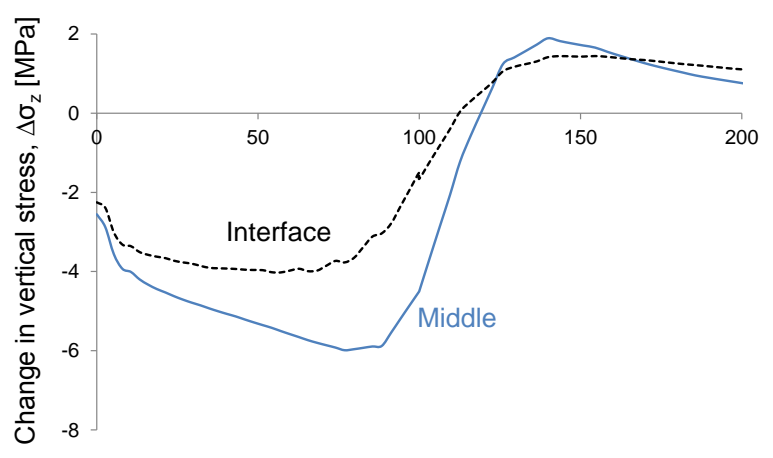

Radial distance (m)

Fig. 2 Numerical simulation results for the injection of cold fluid. (a) Thermal propagation in the entire simulation model. (b) Temperature and pressure graphs (solid linetemperature along the middle line of the injection zone, dotted line-temperature along the injection zone-caprock interface, and dashed line-pressure along both the middle and interface lines). (c) Change in the total radial stress $\Delta \sigma_{r}$. (d) Change in the total vertical stress $\Delta \sigma_{z}$ in the near field. Note: Results are after 1 year of injection. 
(a)

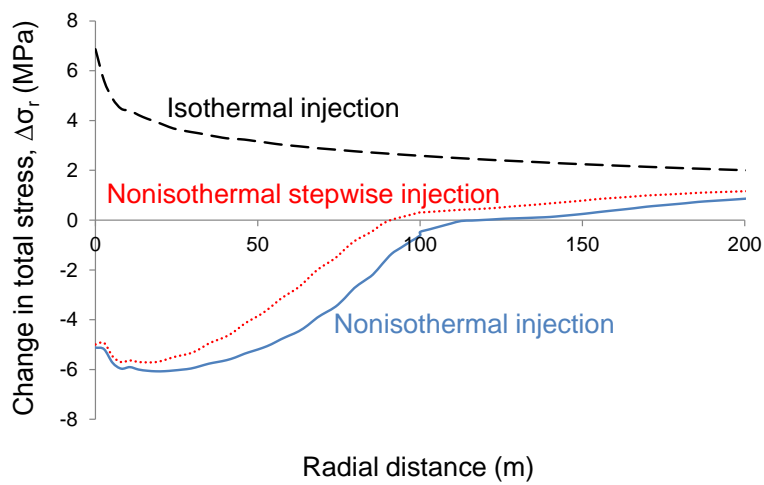

(c)

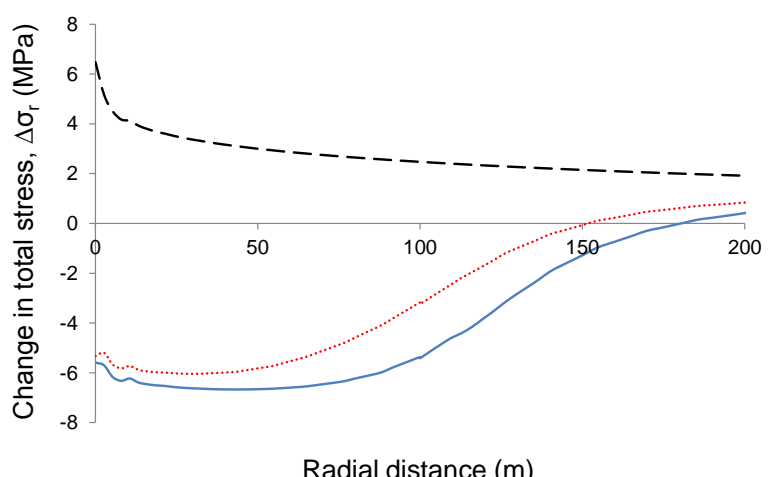

12

13

14

15

16

17 (b)

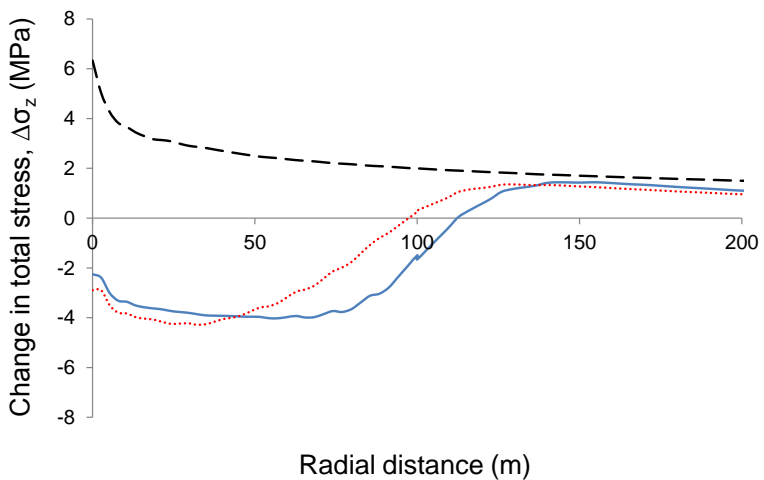

(d)

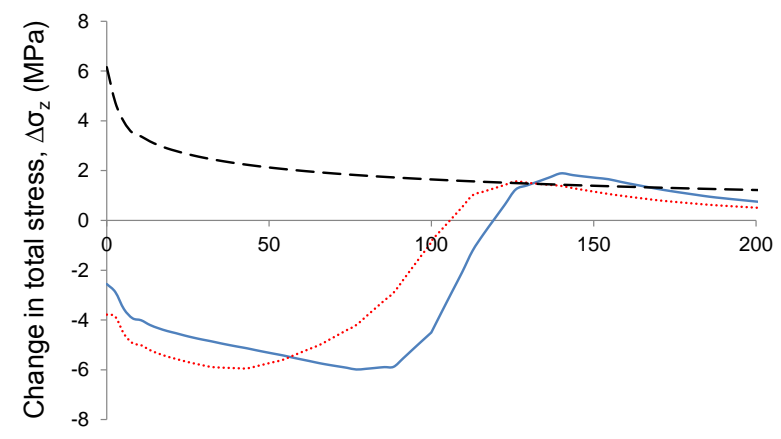

Radial distance $(\mathrm{m})$

Fig. 3 Comparison of changes in total stresses among isothermal fluid injection (dashed line), nonisothermal cold fluid injection (solid line), and stepwise injection of nonisothermal cold fluid (dotted line). Changes in (a) total radial stress $\Delta \sigma_{r}$, and (b) total vertical stress $\Delta \sigma_{z}$ at the injection zone-caprock interface. Changes in (c) total radial stress $\Delta \sigma_{r}$, and (d) total vertical stress $\Delta \sigma_{z}$ in the middle of the injection zone. 
(a)

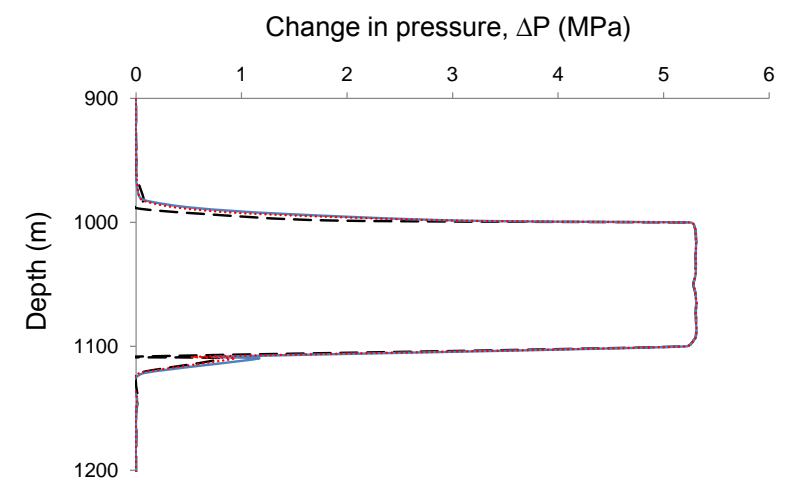

(c)

Change in total stress $\Delta \sigma_{\mathrm{r}}(\mathrm{MPa})$

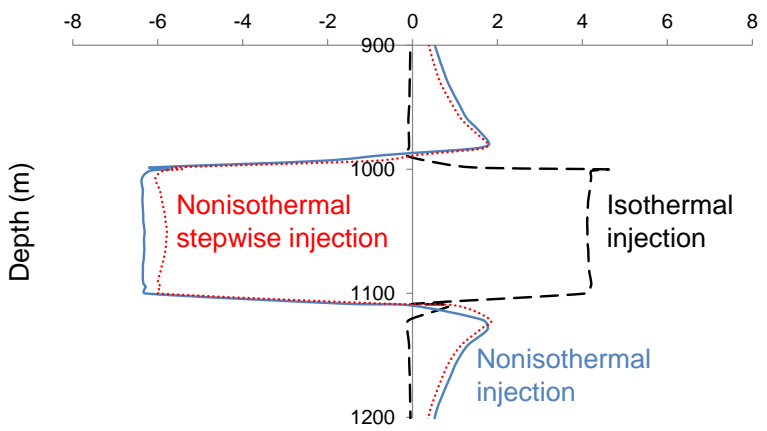

(b)

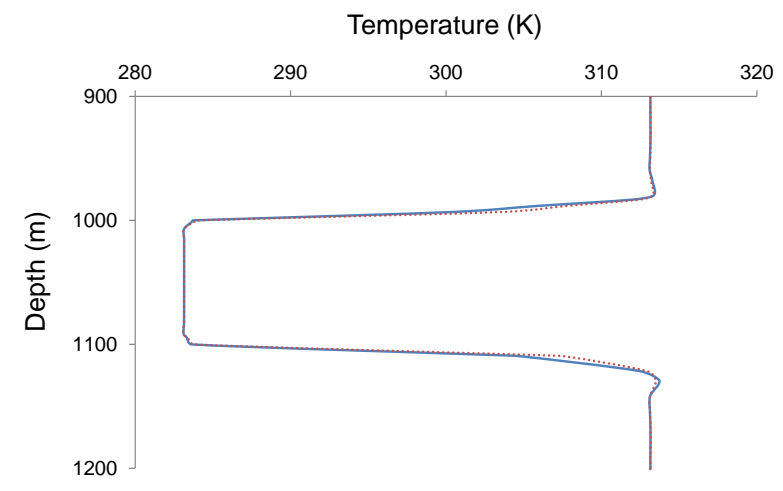

(d)

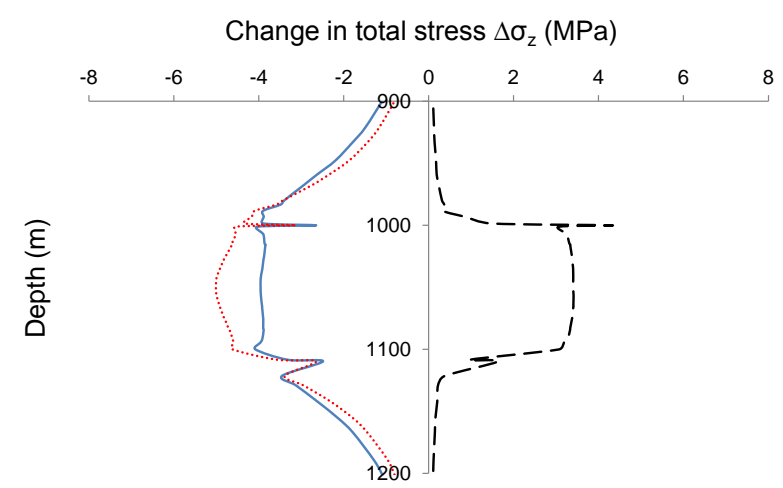

19 Fig. 4 Changes in pressure, temperature, and stresses along the vertical line located $10 \mathrm{~m}$ away from the injection well. (a) Pressure build-up, (b) temperature, (c) change in total radial stress, and (d) change in total vertical stress at the end of the injection. 
(a)

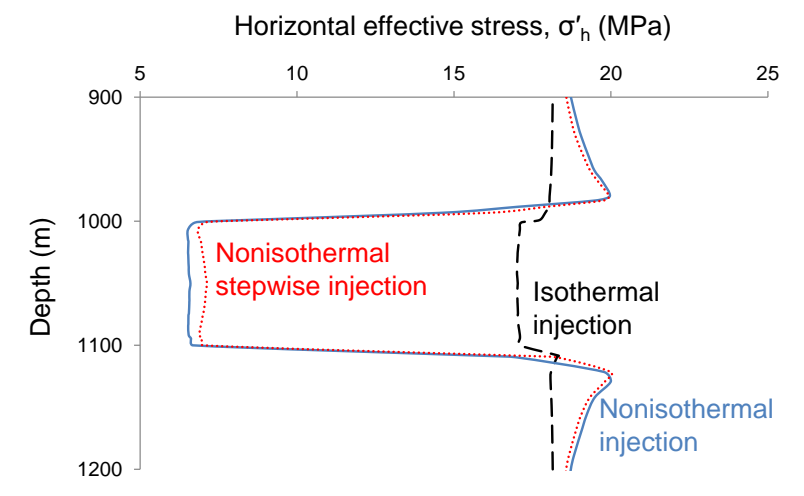

(c)

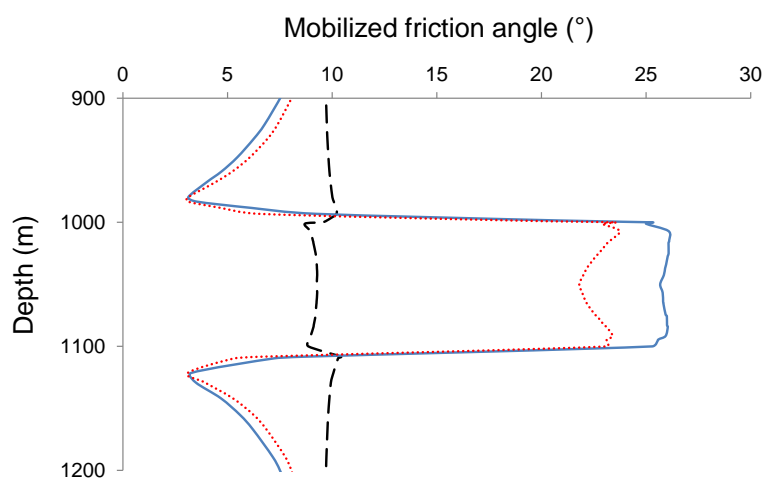

(b)

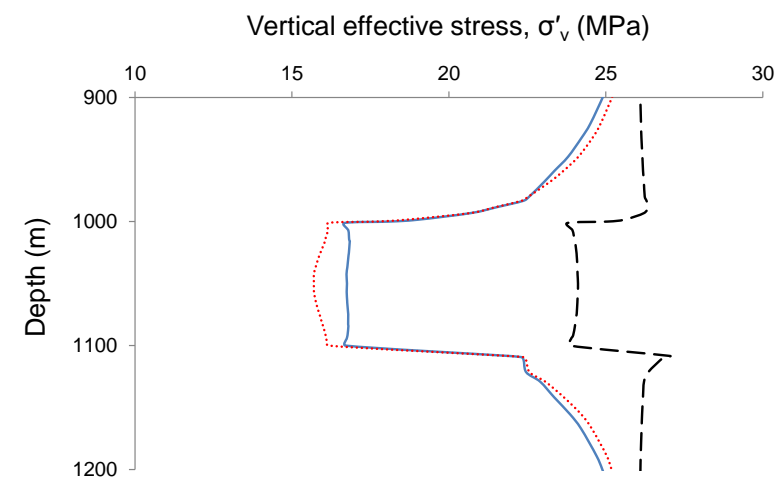

23 Fig. 5 Analysis for the normal-faulting stress regime $(\mathrm{K}=0.7)$. Final values at the end of the 24 injection: (a) horizontal effective stress, (b) vertical effective stress, and (c) mobilized friction angle along the vertical line located $10 \mathrm{~m}$ away from the injection well. 
(a)

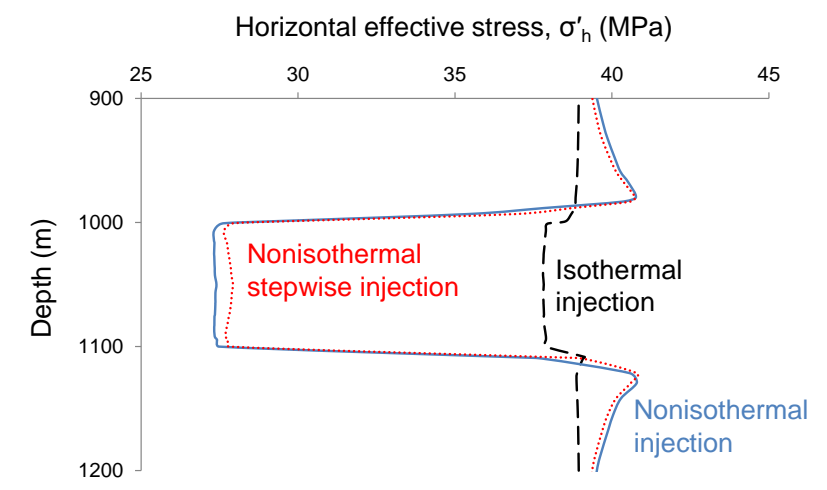

(c)

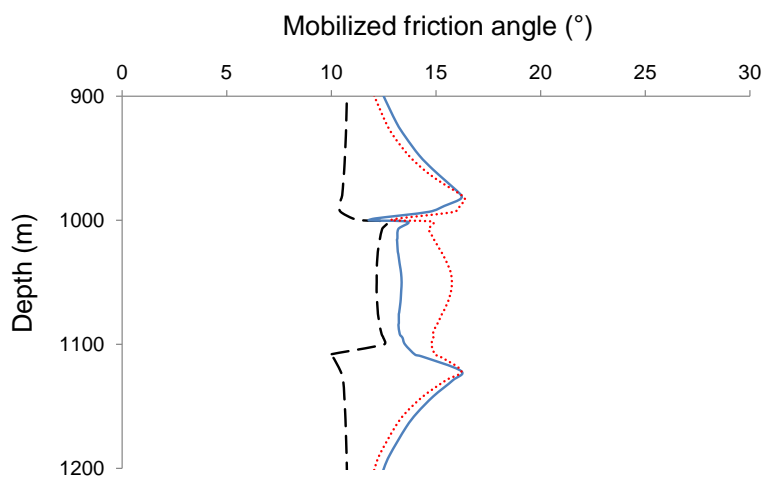

(b)

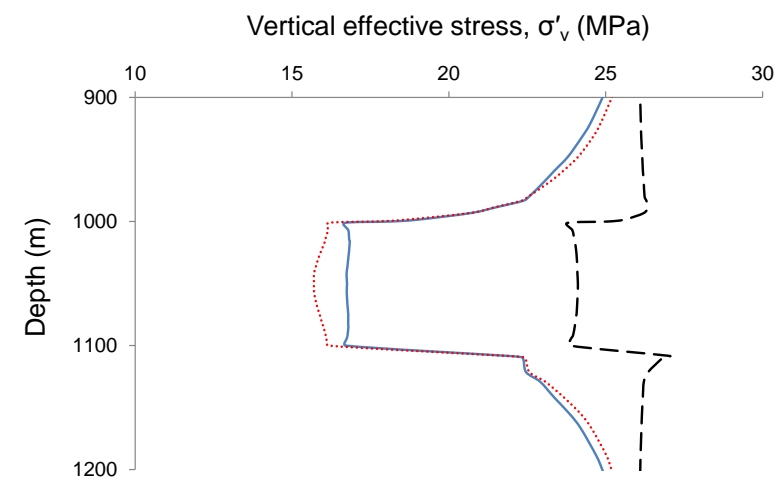

Fig. 6 Analysis for the reverse-faulting stress regime $(K=1.5)$. Final values at the end of the injection: (a) horizontal effective stress, (b) vertical effective stress, and (c) mobilized friction angle along the vertical line located $10 \mathrm{~m}$ away from the injection well. 
(a)

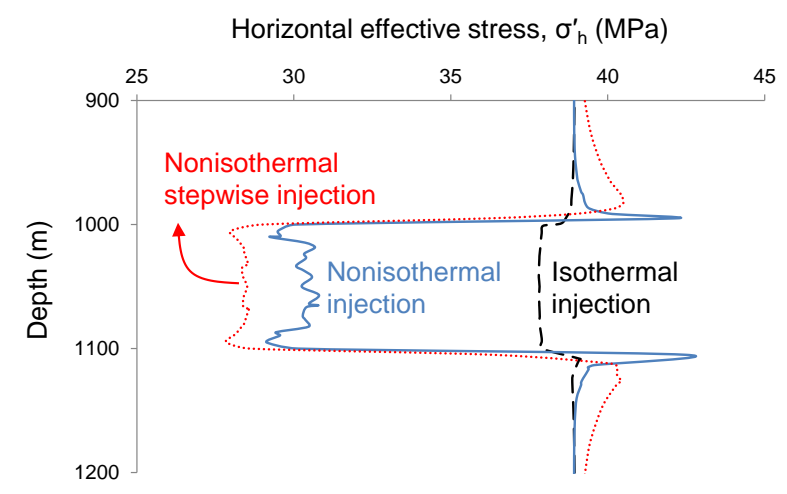

(c)

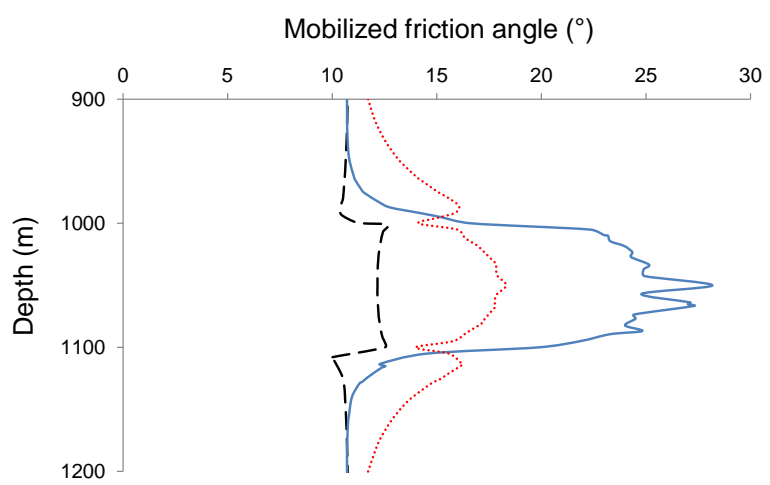

(b)

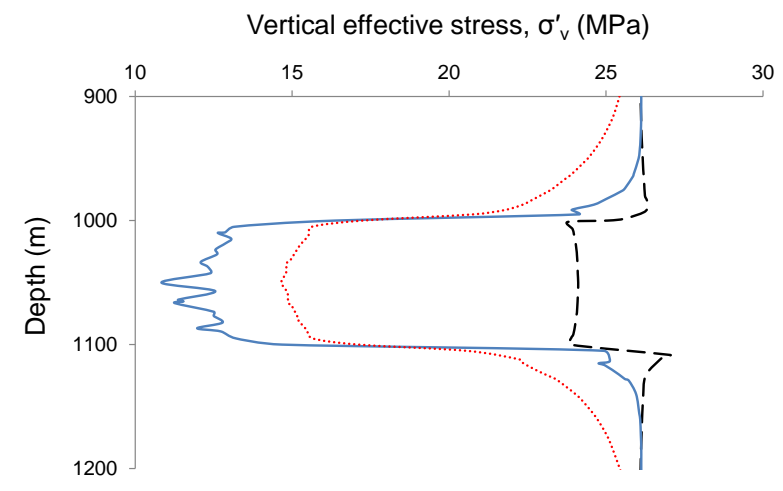

Fig. 7 Analysis for the reverse-faulting stress regime $(K=1.5)$ after 9 days (nonisothermal cold fluid injection) and 542 days (stepwise injection of cold fluid) of operation. Values of: (a) horizontal effective stress, (b) vertical effective stress, and (c) mobilized friction angle along the vertical line located $10 \mathrm{~m}$ away from the injection 35 well. 
(a)

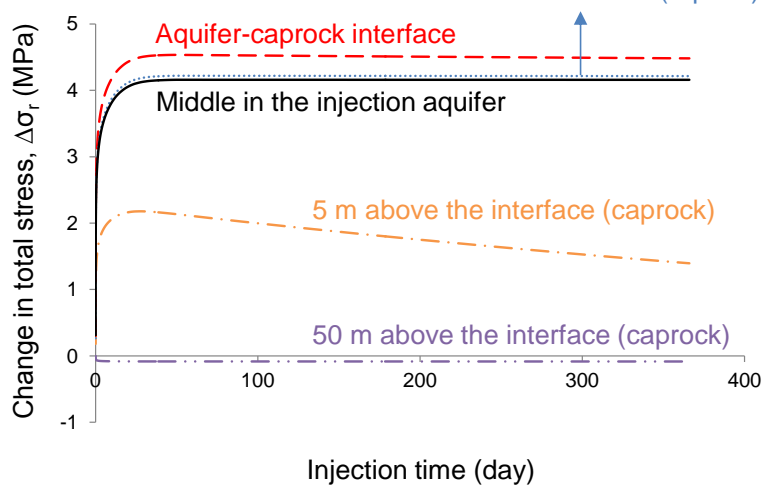

(c)

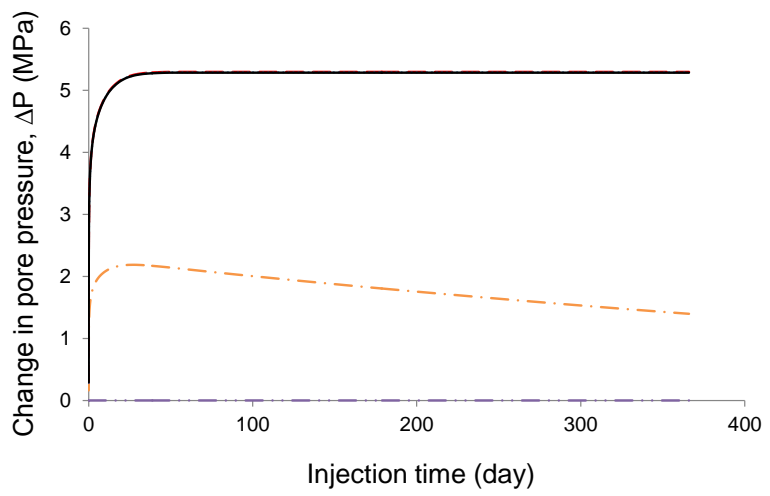

(b)

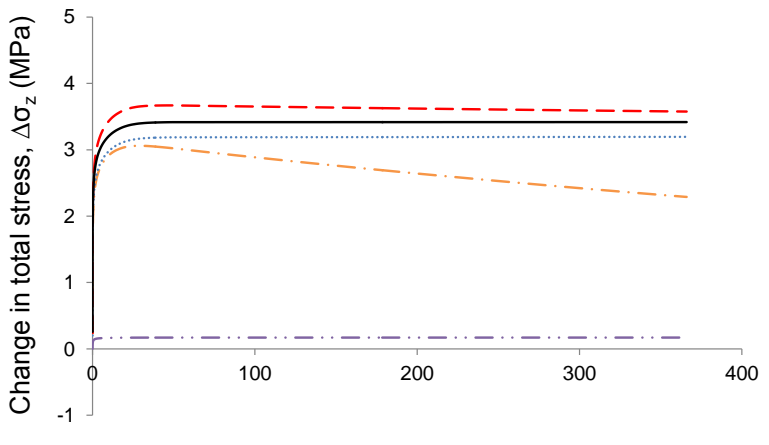

Injection time (day)

Fig. 8 Temporal evolution of changes in stresses and pressure for the isothermal fluid injection. Change in (a) total radial stress, (b) total vertical stress, and (c) pore pressure. Note: All points are radially $10 \mathrm{~m}$ away from the injection well. 
(a)

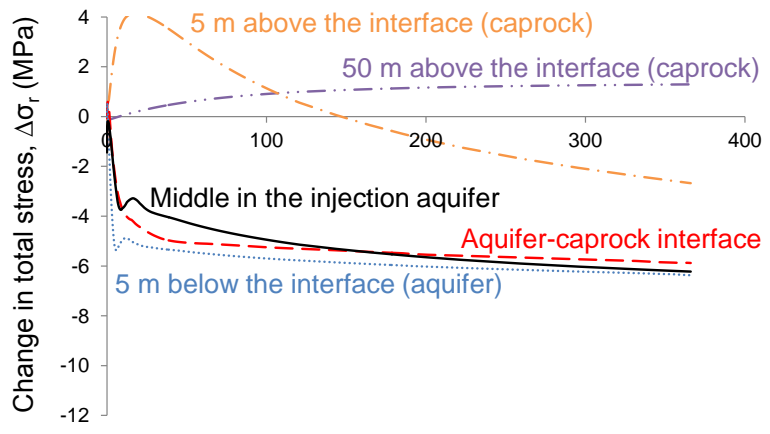

Injection time (day)

(c)

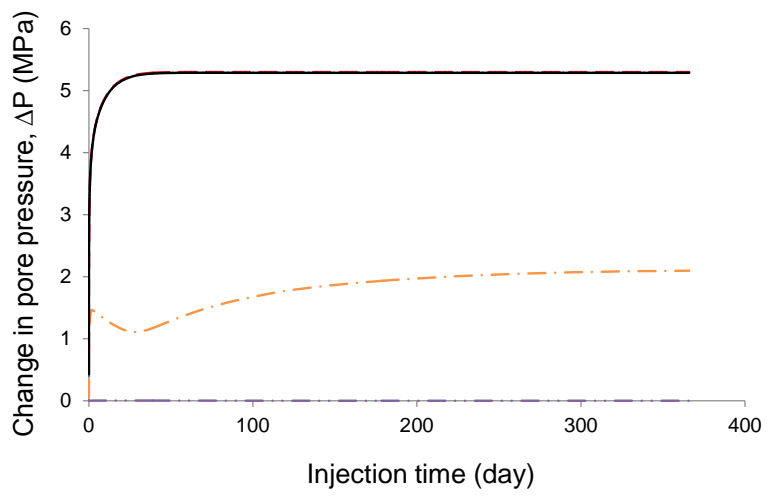

(b)

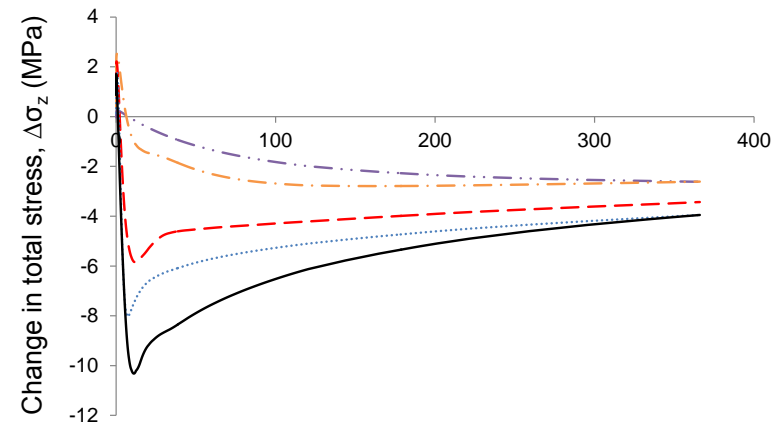

Injection time (day)

(d)

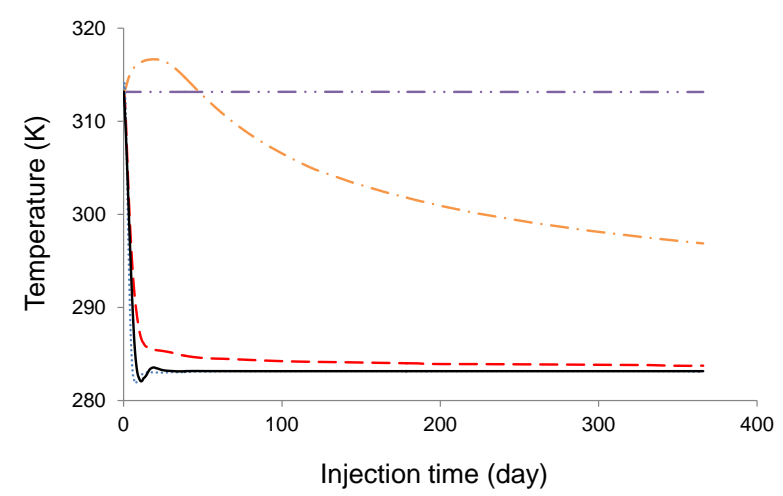

40

Fig. 9 Temporal evolution of changes in stresses, pressure, and temperature for the 42 nonisothermal cold fluid injection. Change in (a) total radial stress, (b) total vertical 43 stress, (c) pore-pressure, and (d) temperature. All points are radially $10 \mathrm{~m}$ away from 44 the injection well. 
(a)

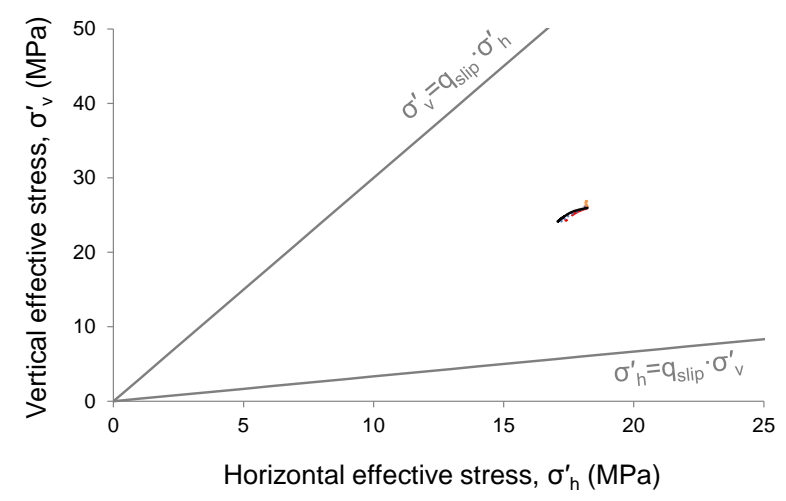

(c) $1.50 \mathrm{~m}$ above the interface (caprock)

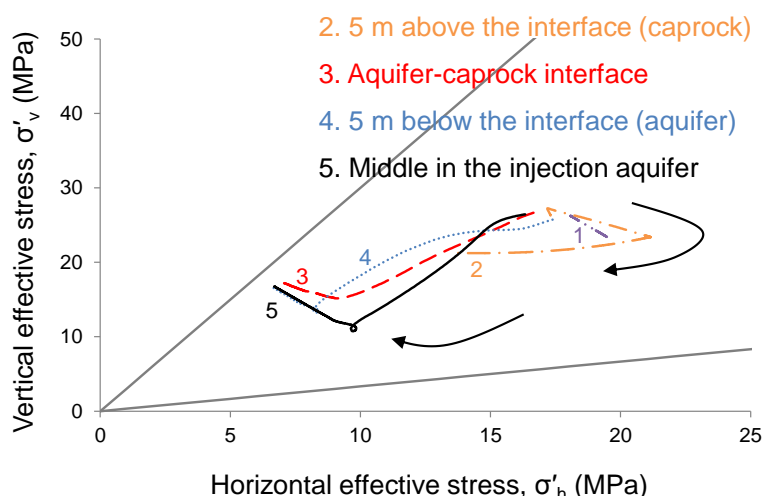

45

46

47

48

49 the injection well. (b)

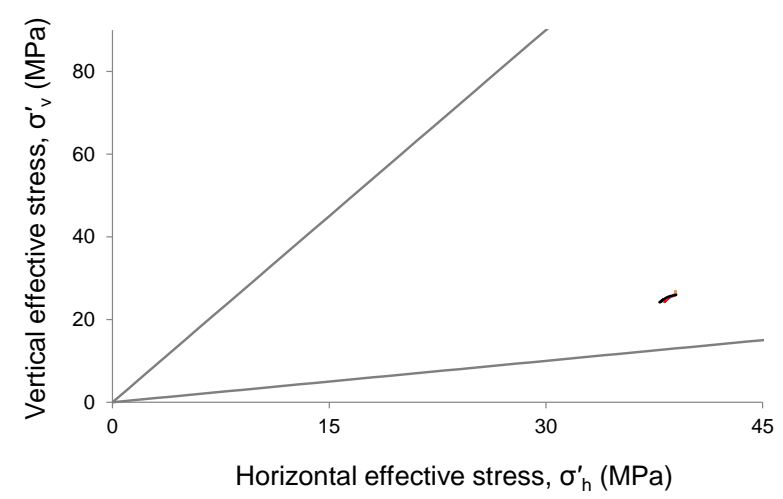

(d)

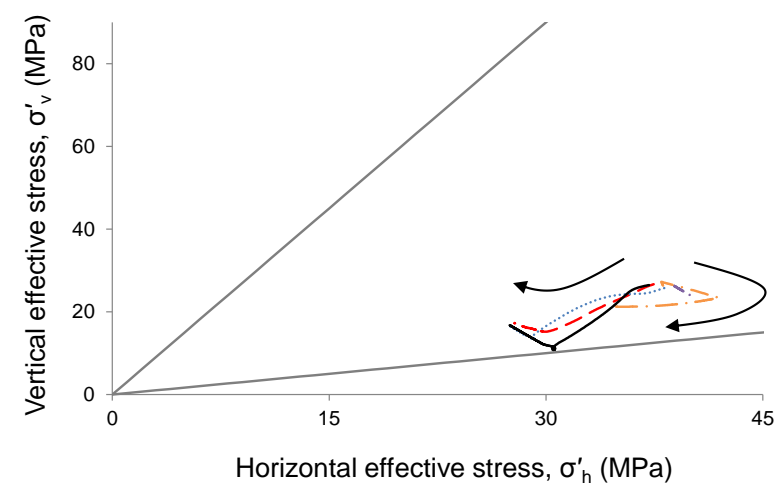

Fig. 10 Stress paths during fluid injection. Isothermal fluid injection: (a) normal-faulting stress regime $(K=0.7)$, and $(b)$ reserve-faulting stress regime $(K=1.5)$. Nonisothermal cold fluid injection: (c) $\mathrm{K}=0.7$, and (d) $\mathrm{K}=1.5$. All points are radially $10 \mathrm{~m}$ away from 
(a)

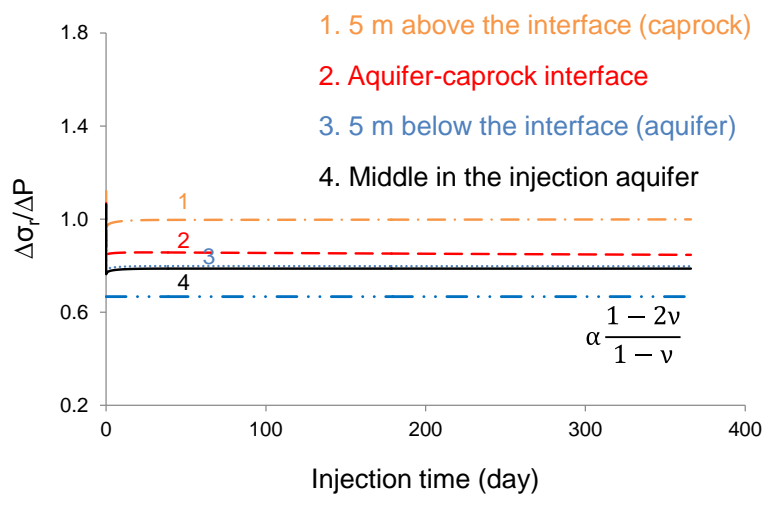

(c)

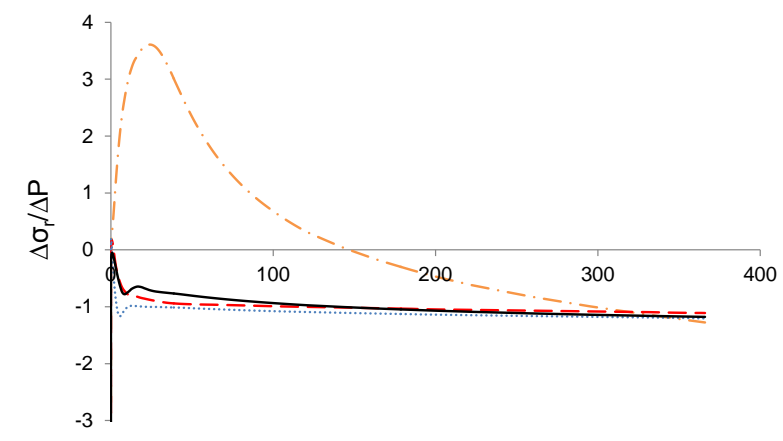

50

51

52

53

54

Injection time (day) injection well. (b)

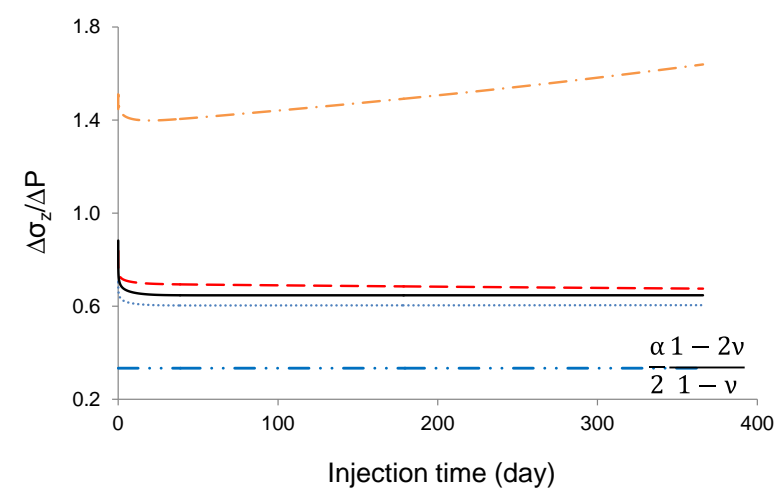

(d)

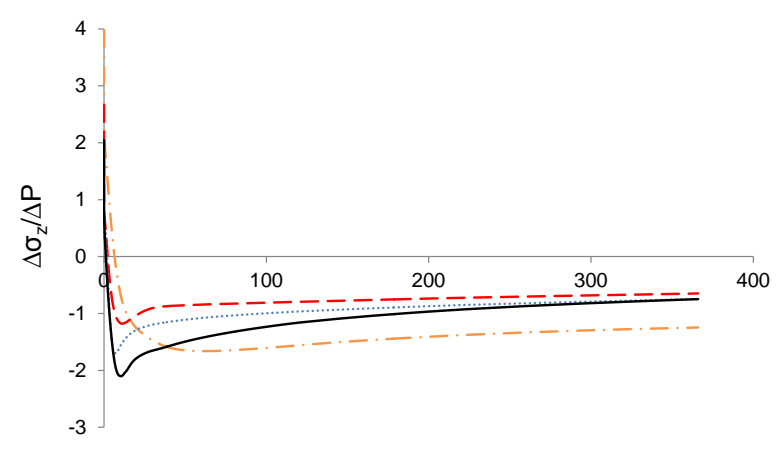

Injection time (day)

Fig. 11 Ratio of stress change to pore-pressure change during fluid injection. Isothermal fluid injection: (a) radial stress, and (b) vertical stress. Nonisothermal cold fluid injection: (c) radial stress, and (d) vertical stress. All points are radially $10 \mathrm{~m}$ away from the 
(a)

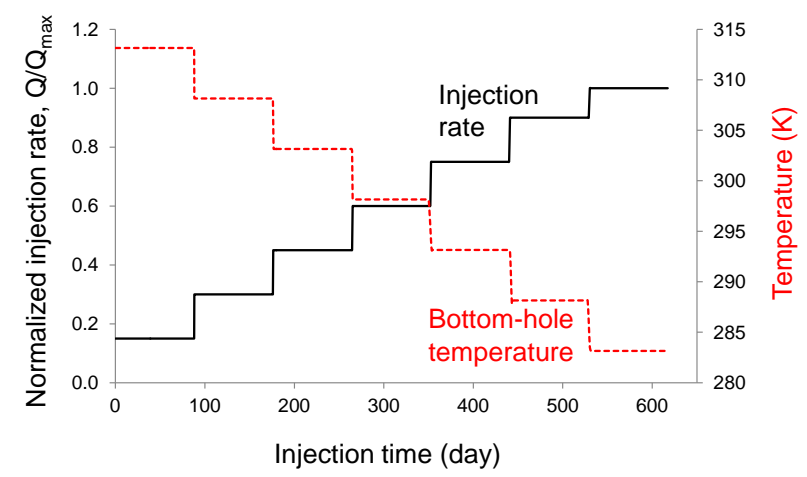

(c)

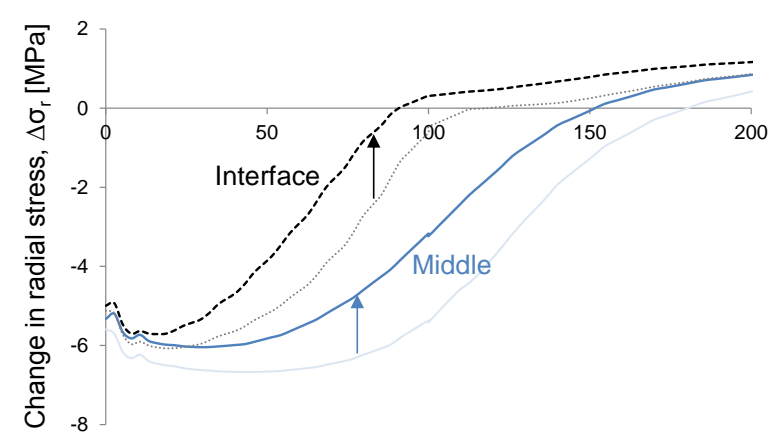

55

56

57

58

59

60 (b)

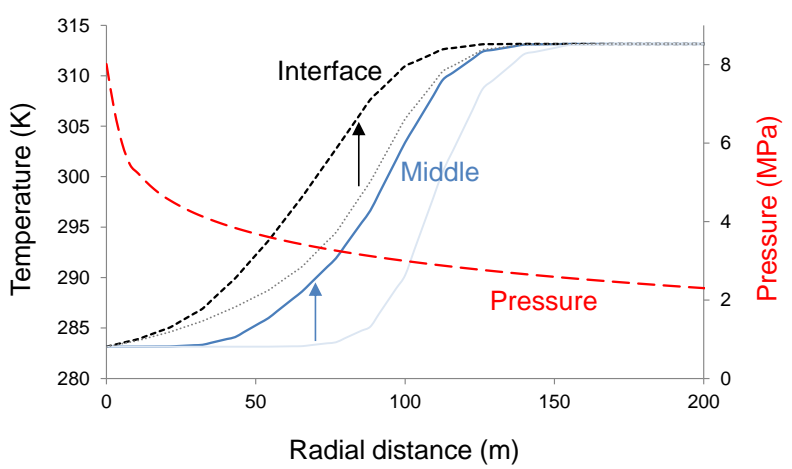

(d)

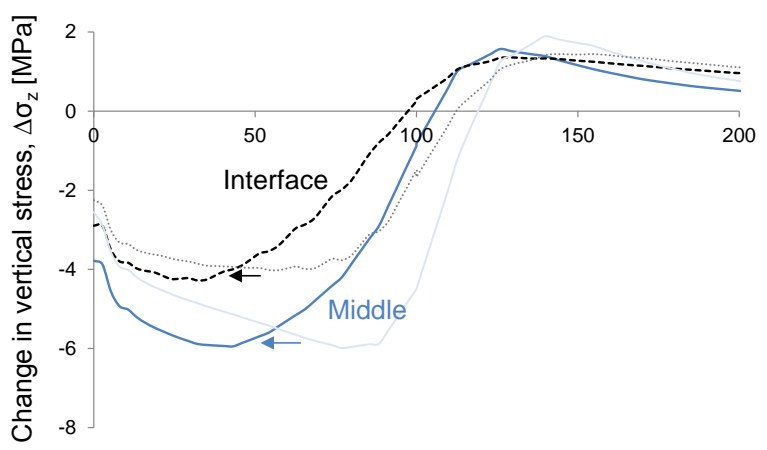

Radial distance $(\mathrm{m})$

Fig. 12 Applying a hypothetical stepwise injection of cold fluid: (a) stepwise increase in injection rate and decrease in bottom-hole temperature during the suggested operation, (b) temperature (solid and dotted lines) and pressure (dashed line) graphs, (c) change in the total radial stress, and (d) change in the total vertical stress in the near field. Results are after 617 days of injection. 
(a)

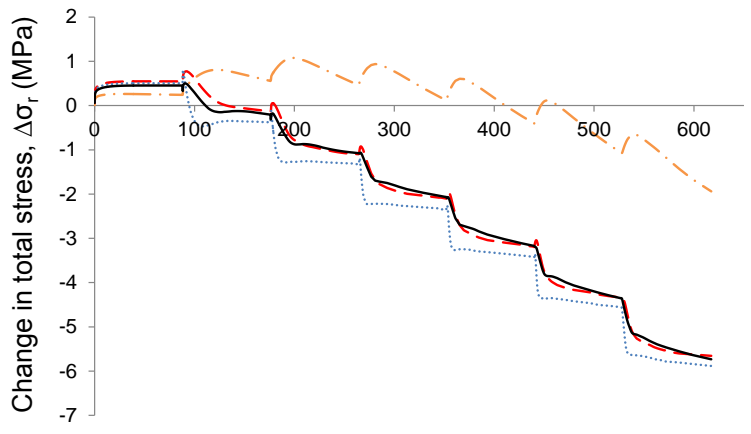

Injection time (day)

(c)

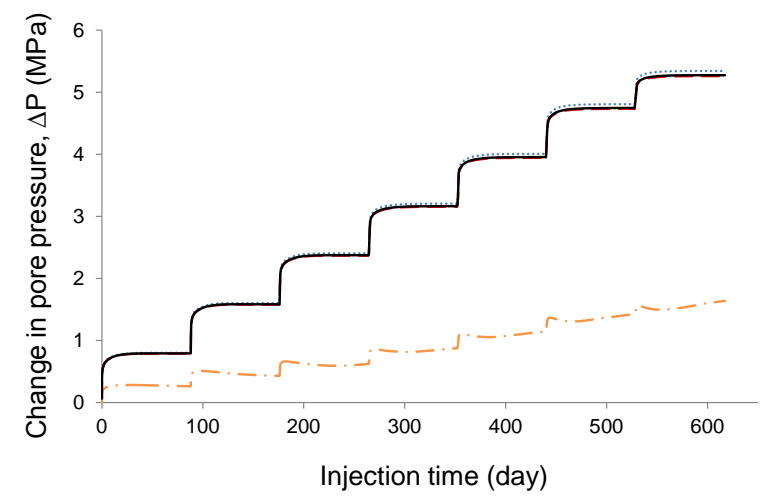

(b)

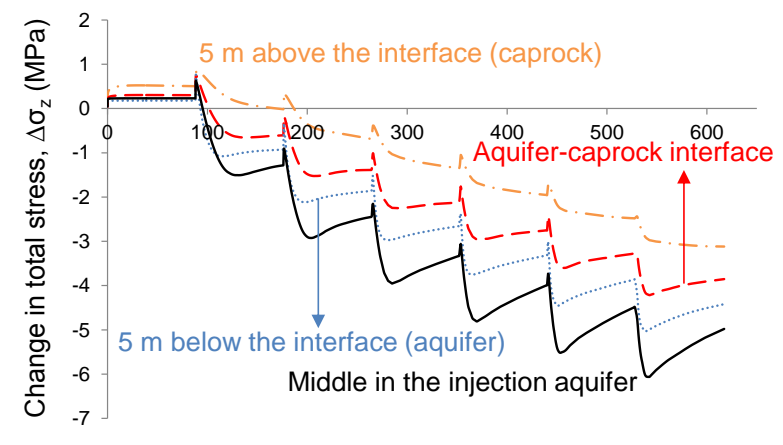

Injection time (day)

(d)

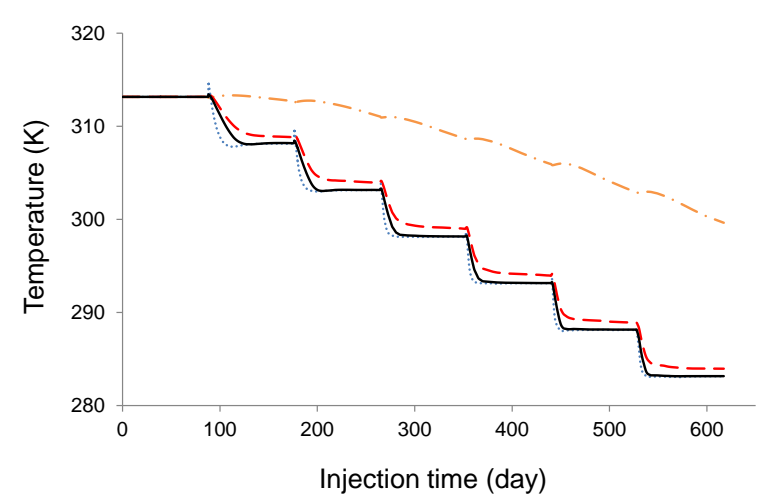

61

62 Fig. 13 Temporal evolution of changes in stresses, pressure, and temperature during the stepwise injection of nonisothermal cold fluid. Change in (a) total radial stress, (b) total vertical stress, (c) pore pressure, and (d) temperature. All points are radially 10 $\mathrm{m}$ away from the injection well. 
(a)

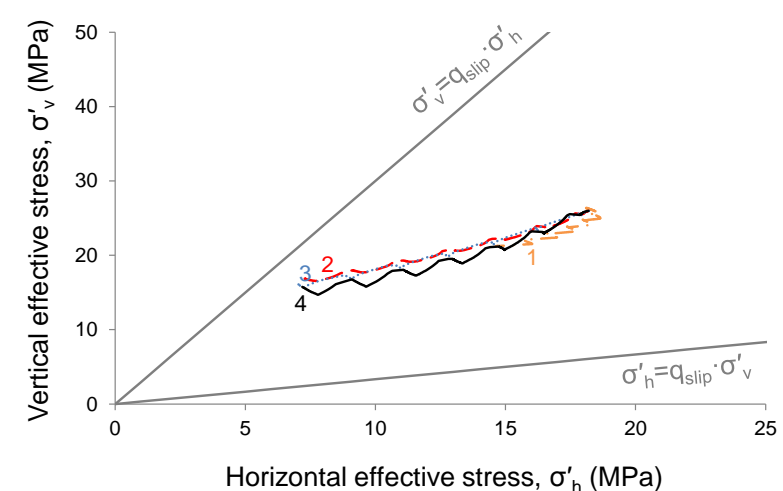

(b) $1.5 \mathrm{~m}$ above the interface (caprock)

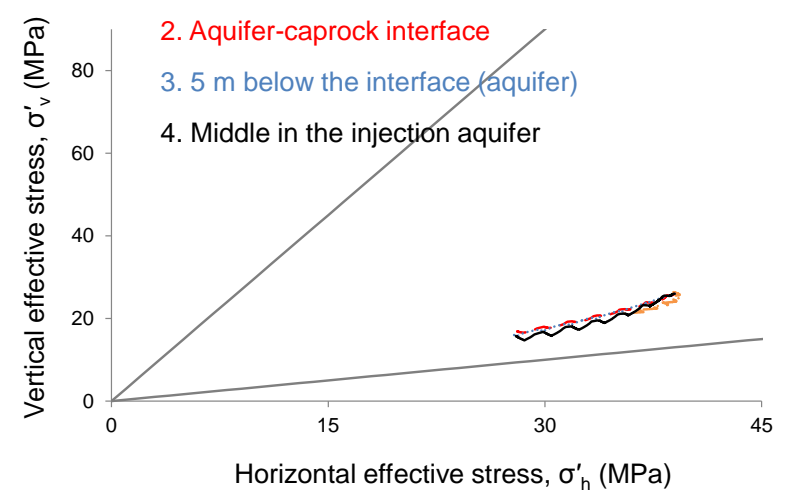

Fig. 14 Stress paths during the stepwise injection of cold fluid. (a) Normal-faulting stress 68 regime $(K=0.7)$, and (b) reserve-faulting stress regime $(K=1.5)$. All points are radially $10 \mathrm{~m}$ away from the injection well. 
(a)

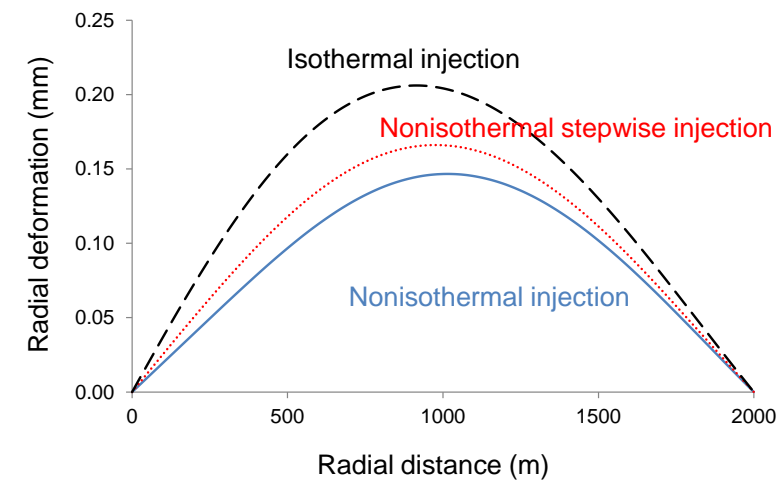

(b)

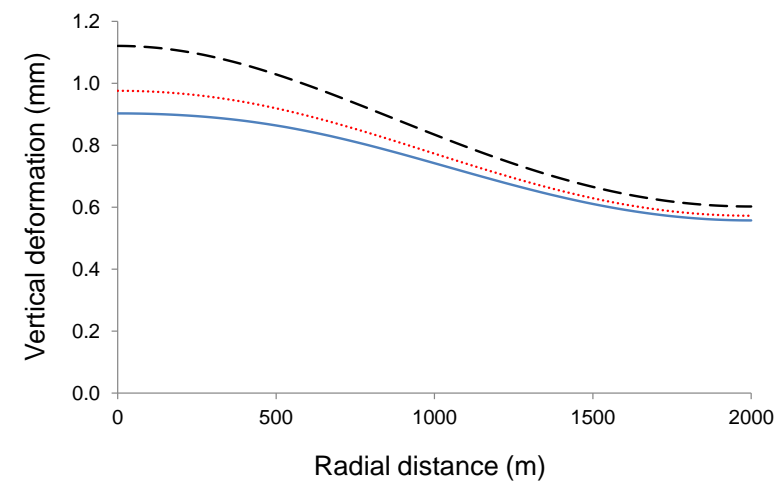

Fig. 15 Surface deformation at the end of fluid injection. (a) Radial, and (b) vertical deformation with radial distance from injection well. 
(a)

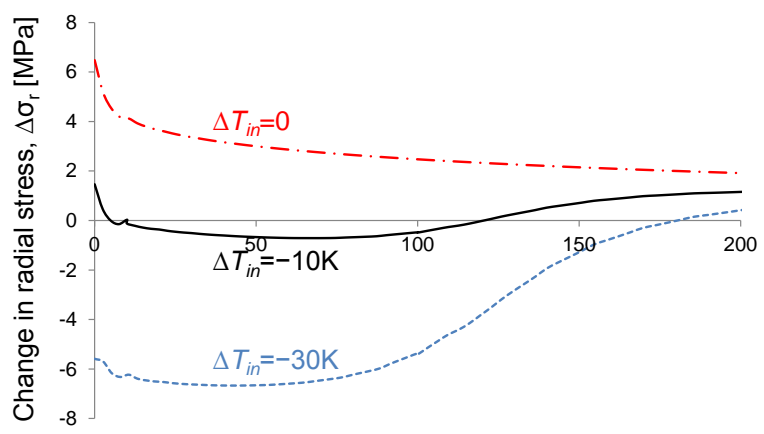

(c)

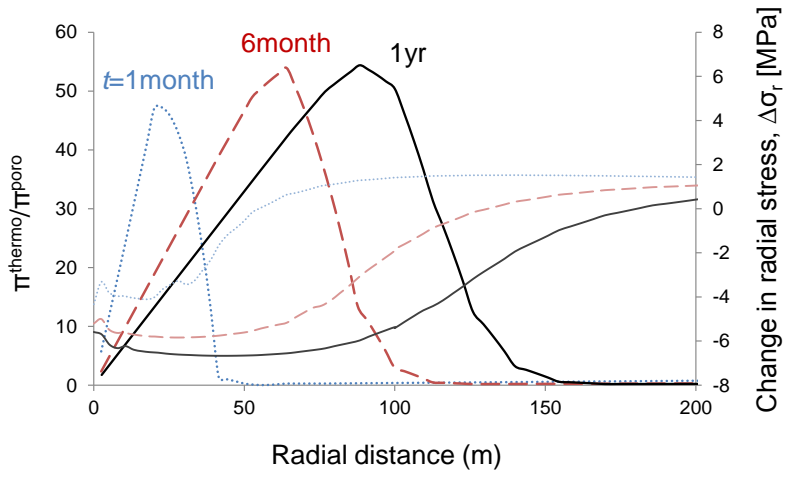

(e)

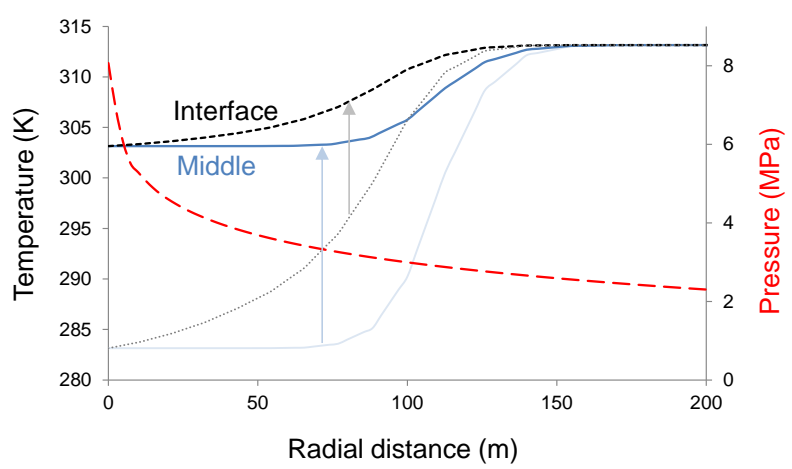

(b)

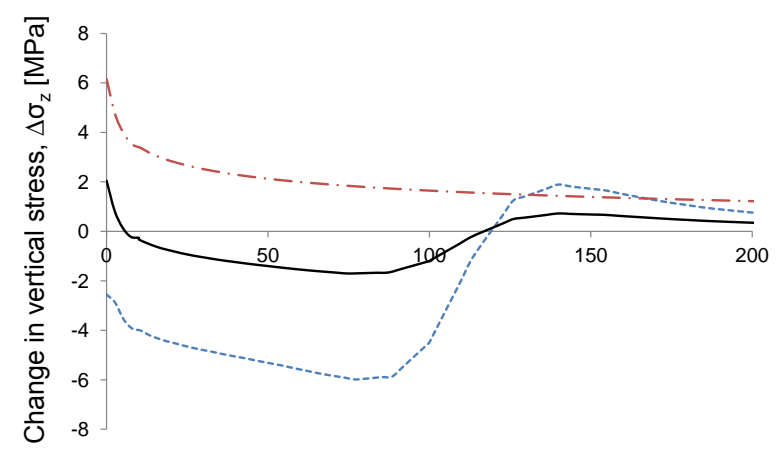

(d)

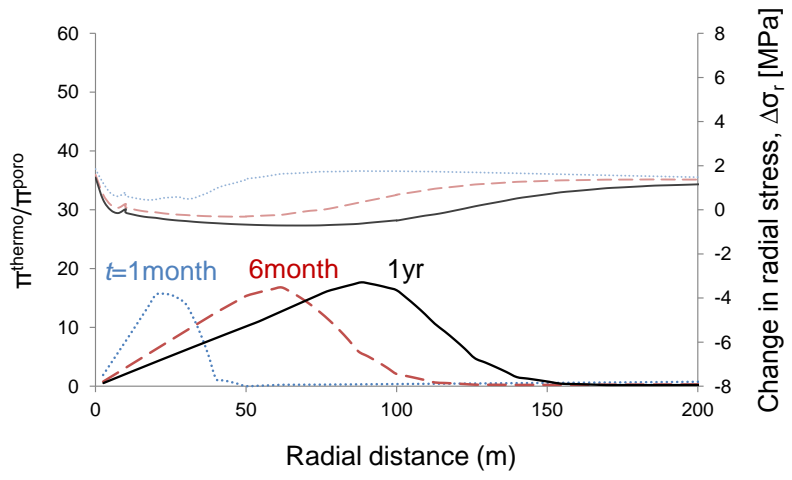

Fig. 16 Comparison between isothermal fluid injection and cold fluid injection at the end of the injection, where $\Delta T_{i n}=-30 \mathrm{~K}$ or $-10 \mathrm{~K}$. (a) Change in the total radial stress, and (b) change in the total vertical stress along the middle line of the injection zone. Ratio of dimensionless parameters $\pi^{\text {thermo }} / \pi^{\text {poro }}$ and corresponding change in the total radial stress (thin graphs) when (c) $\Delta T_{i n}=-30 \mathrm{~K}$ and (d) $\Delta T_{i n}=-10 \mathrm{~K}$. (e) Temperature distribution along the middle line (solid) and the interface line (dotted) when $\Delta T_{\text {in }}=$ $-10 \mathrm{~K}$ (thin lines are when $\Delta T_{\text {in }}=-30 \mathrm{~K}$ ). 